\title{
Advanced Thermoplastic Composite Manufacturing by In-Situ Consolidation: A Review
}

\author{
Isabel Martin $^{1}$, Diego Saenz del Castillo ${ }^{1} \mathbb{D}$, Antonio Fernandez ${ }^{2}$ (D) and Alfredo Güemes ${ }^{2, *(\mathbb{D})}$ \\ 1 FIDAMC, Foundation for the Research, Development and Application of Composite Materials, \\ Avda. Rita Levi Montalcini 29, Tecnogetafe, Getafe, 28906 Madrid, Spain; \\ Maria-Isabel.Martin@fidamc.es (I.M.); Diego.Saenz@fidamc.es (D.S.d.C.) \\ 2 E.T.S.I. Aeronáutica y del Espacio, Universidad Politécnica de Madrid, Pza. de Cardenal Cisneros 3, \\ 28040 Madrid, Spain; antonio.fernandez.lopez@upm.es \\ * Correspondence: alfredo.guemes@upm.es
}

Received: 23 August 2020; Accepted: 10 October 2020; Published: 13 October 2020

\begin{abstract}
This article provides an overview of the evolution of the in-situ consolidation (ISC) process over time. This evolution is intimately linked with the advancements in each of the steps of the ISC manufacturing process, is additive in nature, and is limited by the orthotropic nature of composite materials and the physicochemical behavior of the thermoplastic matrix. This review covers four key topics: (a) Thermal models-simulation tools are critical to understand a process with such large spatial gradients and fast changes. Heating systems once marked a turning point in the development of industrial ISC systems. Today, lasers are the most recent trend, and there are three key issues being studied: The absorption of energy of light by the material, the laser profile, and the laser focusing. Several approaches have been proposed for the distributed temperature measurements, given the strong temperature gradients. (b) Adhesion-this refers to two subsequent mechanisms. In the first place, the process of intimate contact is one by which two surfaces of thermoplastic pre-impregnated composite materials are brought into contact under pressure and temperature. This enables closure of the existing gaps between the two microscopic irregular surfaces. This process is then followed by the healing or diffusion of polymer molecules across the interface. (c) Crystallinity-mostly influenced by the cooling rate, and strongly affects the mechanical properties. (d) Degradation - this refers to the potential irreversible changes in the polymer structure caused by the high temperatures required for the process. Degradation can be avoided through adequate control of the process parameters. The end goal of the ISC manufacturing process is to achieve a high product quality with a high deposition rate through an industrial process competitive with the current manufacturing process for thermoset composites.
\end{abstract}

Keywords: thermoplastic composites; automatic lamination; in-situ consolidation; aircraft structures; laser assisted tape placement

\section{Introduction}

The key properties that justify the wide use of composite materials in the aeronautical industry were described in [1] including weight savings due to the increase of specific resistance and stiffness, which leads to reductions in fuel consumption and, consequently, allows an increase in aircraft payload. Furthermore, the specific properties are not the only driver for material selection for aerospace applications - costs are also important. It is necessary to demonstrate how affordable it is to manufacture and use materials during operation. Any selected material must also have the ability to withstand stresses in the presence of typical damages, durability, resistance to fatigue, and environmental degradation. 
The carbon-thermoset matrix composite materials meet the vast majority of the requirements described above, improving the performances over typical light metal alloys. Despite its potential, the application of these materials to aeronautical parts has been very progressive until full confidence on the in-service behavior has been demonstrated, and the strict certification process required for the composite structures is fulfilled.

The application of thermoplastic polymeric matrix materials has not currently reached the same levels of development as those already attained with thermosets. The high process temperature requirements and the lower productivity achieved with thermoplastics are among the possible reasons for this delay. In thermoplastic composite reinforced materials, at room temperatures the material is in solid state and has no tackiness, a crucial property for the thermoset automatic layup process. Additionally, at temperatures above the melting point, the viscosity values are still very high, as the matrix is already in a polymerized state. This makes higher temperatures and pressures necessary and, therefore, the processes have higher costs than thermosets.

Positive properties for the development of thermoplastic material include the possibility of manufacturing structures with high levels of integration, avoiding the need for subsequent assembly processes, and practically unlimited life without the need for refrigeration and low risk of contamination or toxicity in human manipulation as the polymer has already been polymerized [2]. Currently, aspects such as sustainability and environmental conservation are also important [3]; thermoplastic materials have the capability to be recycled. The possibility of making a future where the parts of retired aircrafts can be reused represents a point in favor of the incorporation of this type of material.

To achieve similar application levels to thermosets in the aeronautical industry, it is necessary to develop new processes for thermoplastics that simplify or reduce costs with respect to current manufacturing processes. Currently, for the manufacturing of large structures with thermoset material, automated layup is used, with layup speeds of the order of $50 \mathrm{~m} / \mathrm{min}$. As the material is partially cured, it preserves its adhesiveness, making it possible to join the different plies. After layup, stacks require shaping and/or vacuum bags for a subsequent autoclave curing step. For their part, thermoplastic reinforced materials have not been able to undergo the same sequence due to the important differences that automatic layup processes have between them.

Shorter cycles are a clear advantage of thermoplastic composite materials compared to conventional ones with thermosets. The lack of tackiness among layers at room temperatures requires an increase in their temperatures to values over their melting point (semi-crystalline) or glass transition (amorphous). However, it also allows the lay-up to be done and simultaneously creates high-quality bonding among layers, suppressing the next curing stages in the oven or autoclave.

Using this idea, the developments that led to the automatic layup process and in-situ consolidation were established, where a heating source heats surfaces of thermoplastic material, subsequently contacting them under the action of a compacting element. This process involves multiple physical parameters that take place simultaneously and whose control is essential to enable the application of improvements in the product. In order to apply this process in a profitable way for the industry, it is necessary to ensure that it is possible to achieve high degrees of consolidation without the need for a second cycle of re-consolidation in the stove or autoclave; references such as [2] report degrees of consolidation around 80-90\%; however, current results from the Automated Dynamics company confirm the possibility of reaching compaction levels comparable to those obtained in stove and autoclave cycles with speeds suitable for industrial production. In the application of the reinforced thermoplastics to aeronautical parts, Ref. [4] points out the need to use them in applications where the temperature limits are close to their glass transition minus $30 \mathrm{~K}$, since over this temperature the softening of the material occurs, modifying its mechanical properties.

The use of thermoplastic composites for long size composite structures requires the development of in-situ consolidation, as it is considered the most promising manufacturing process capable of reducing manufacturing time and cost. The first patent referring to this process dates from 1986, associated with DuPont [5] (layup method and equipment patent), where the outstanding point is the 
approach of applying the automatic layup to a thermoplastic material using a secondary pre-heating source on the substrate and a main source that acts between said substrate and the material being supplied, with an energy distribution between the substrate and incoming tape of 20-80\%. Northrop Corporation, the American aircraft manufacturer, issued a patent on this topic in 1991 [6]. Among the particularities of its proposal, it presents the use of a heated roller, a cooling system just at the exit of the roller (compactor foot), and the interposition of a sheet of material between the roller and the material to be taped to avoid adhesion between them. The patent also presents a working system for the first layer layup based on the use of a perforated tool from which a vacuum will be applied to the taped material, between the tool and the piece a layer of insulating glass and a film of Kapton.

In 1997, the Boeing Company was the assignee of a patent on a multi-wick wrapping machine (at least two wicks of material). A detailed description of each of the components of the equipment was reported in the patent, giving specific details about the compaction roller. The proposed system consisted of cavities with air circulating for cooling, equipped with a component that allowed it to be tilted (axis of rotation in the direction of the layup) to enable the application of pressure on all the tows in non-flat layup conditions. The Boeing Company in 2002 also protected its work on the heating method and the heating control system in the process of layup of composite materials, without specifying the type [7]. In the previous patent, the heating system used was a group of diode lasers that allowed control of the energy supplied in the longitudinal and transverse directions of the layup, favoring concave-convex tapes and with different inclinations of the substrate. As a control system they used a thermography measurement system.

Aerospatiale, the French aerospace company which would later become part of the European business conglomerate, Airbus, filed a patent in 2003 which protected the development of a layup with integration, with a technology known as co-consolidation [8]. The patent considers the lamination of a skin on the stiffeners the consolidated skin and the stiffeners joined by diffusion/conduction welding, indicating a preferred application of this system in the manufacture of fuselage segments or engine covers.

The already-formed Airbus patented another methodology for thermoplastic layup in 2011 [9], in which a part of the layup tool was made of porous material. The proposal included the use of a microporous aluminum positioned on the surface of a larger non-porous tool. The size of the cavities was small enough so that, together with the high viscosity of the polymer, they cannot block or affect the surface quality of the part. This system can also help in the de-molding stage, if the change from negative to positive pressure on the part is carried out.

Machine manufacturers have also protected their advances with patents. Cincinnati Milacron, Inc. protected heating control in the thermoplastic layup process [10], and Automated Dynamics protected their technology with various patents [11-15], related to the layup equipment, layup material, and manufacturing technology for the incorporation of lightning protection systems. For its part, in 2008 Accudyne Systems, Inc. launched a patent for equipment and processes for the layup of thermoplastic composite material [16] highlighting the proposal for the use of a flexible compaction system consisting of segments that apply pressure independently. The company that produces robotic cells for the layup of composite materials, Coriolis Composites, patented in 2016 [17] an innovative solution for the compaction roller, in line with the solution proposed by Accudyne. The solution was based on the fact that each of the segments that make up the roller are in turn cylinders with an interior made up of elements with curvatures that give it greater flexibility.

Concerning the scientific production, Figure 1 gives the evolution of the number of documents found at the Scopus database with the words "thermoplastic composite manufacturing" appearing either in the title, keywords, or abstract. About half of these documents were journal articles, while the other half were mainly papers submitted to scientific conferences (ICCM, Sampe, and similar). By adding the word "consolidation" to the search, the number of documents was reduced to 10-20\%. We may conclude that the number of publications per year was consistently maintained, but not very 
high compared to other topics in Composites. Most of these papers have been reviewed for this work, and roughly half of them are included in the reference list.

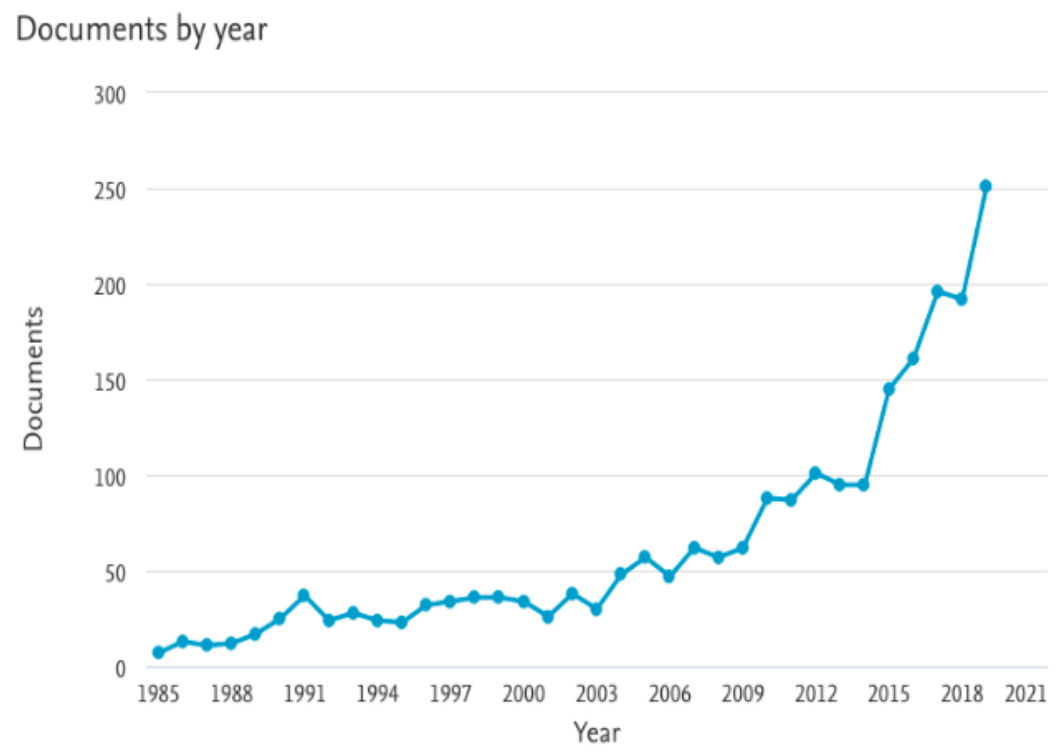

(a)

Documents by year

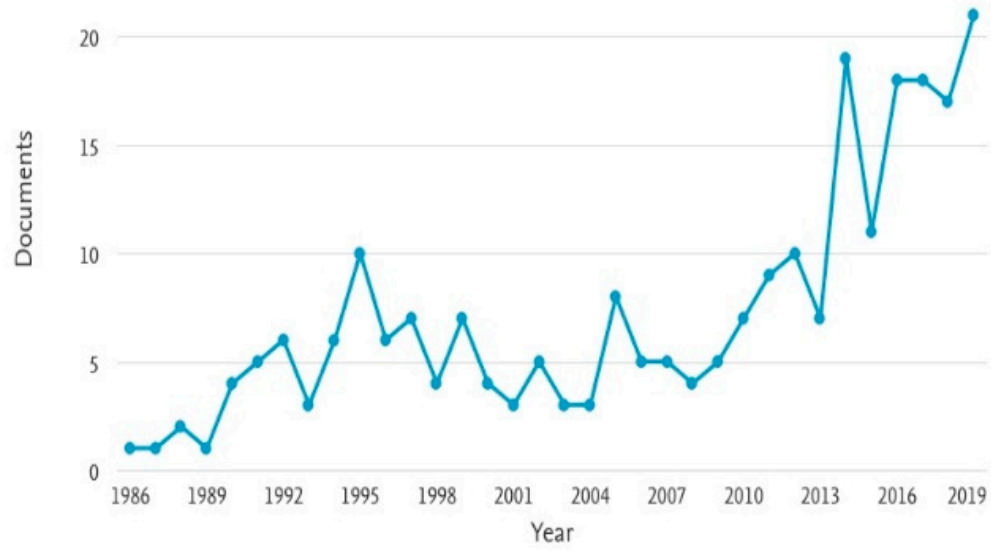

(b)

Figure 1. Documents in the Scopus database under "thermoplastic composite manufacturing" (a) and "thermoplastic composite manufacturing consolidation" (b).

This article is organized as follows: After the Introduction, Section 2 details of the ISC machines, its evolution over time, and the reasons for it. Section 3 is called "Thermal Models", because it was recognized early that a process with such a large spatial gradients and very fast changes (the material melts and cool within seconds in a small region of the laminate) could not be understood without the help of simulation tools. A point of interest was the heating systems, and the absorption of light energy by the material, as lasers are a recent trend, driven by the need of focusing the power input. Different solutions have been proposed for the distributed temperature measurements, because of the localized large gradients. Next, Section 4 is a review on the "Adhesion", or mechanisms by which two surfaces of thermoplastic composite materials brought into contact, by the application of pressure 
and temperature, are able to close the existing gaps due to the inherent irregularity of the surfaces of the material before its manufacturing process. Two other quite important related topics are Sections 5 and 6, respectively: (5) Crystallization, a characteristic of some thermoplastic materials that benefits its mechanical properties, particularly toughness, and solvent resistance; the percentage of crystallinity and morphology is linked to the thermal profile. (6) Degradation, when a polymer is exposed to very high temperatures over the melting point, even for seconds.

This article has been extracted from the Doctoral Thesis of the first author, written in Spanish and available in Ref. [18]. This survey has been kept opened to every fiber/thermoplastic matrix system, even though carbon fiber/PEEK is the system that has received more attention. Poly-ether-ether-ketone, commonly referred to as PEEK, is a semi-crystalline polymer with a glass transition temperature of $143^{\circ} \mathrm{C}$, and a melting point of $343^{\circ} \mathrm{C}$. Worthy to remember that processing temperature needs to be higher than melting point, while $\mathrm{Tg}$ is the maximum service temperature as a composite material, because the drop of stiffness in the matrix for temperatures higher than this value implies a drop of longitudinal compressive strength of the laminate.

\section{Automatic Lamination and In-Situ Consolidation (ISC)}

The automatic lamination and in-situ consolidation process with thermoplastic reinforced material has been studied since the 1980s [19]. Most of the initial references based on this process refer to the development of laminates where it is not possible to obtain a total degree of bonding between the parts, making a second consolidation stage necessary [20]. It was estimated that the speeds required to obtain a real in-situ consolidation were about $0.5 \mathrm{~m} / \mathrm{s}$.

The reasons that lead to consideration of this manufacturing process as advantageous are the reduction of costs due to a limited amount of scrap or excess material in the tapes, improvements in the positioning of the material, repetitive results, and lower labor costs. It is also an essential step for the development of large structures [21].

The basic outline of this process is included in Figure 2. Plies of reinforced thermoplastic material adhere to each other after increasing their temperature due to the heating generated by a thermal source (laser or any other type) and by bringing them into contact with the application of pressure by means of a compacting roller.
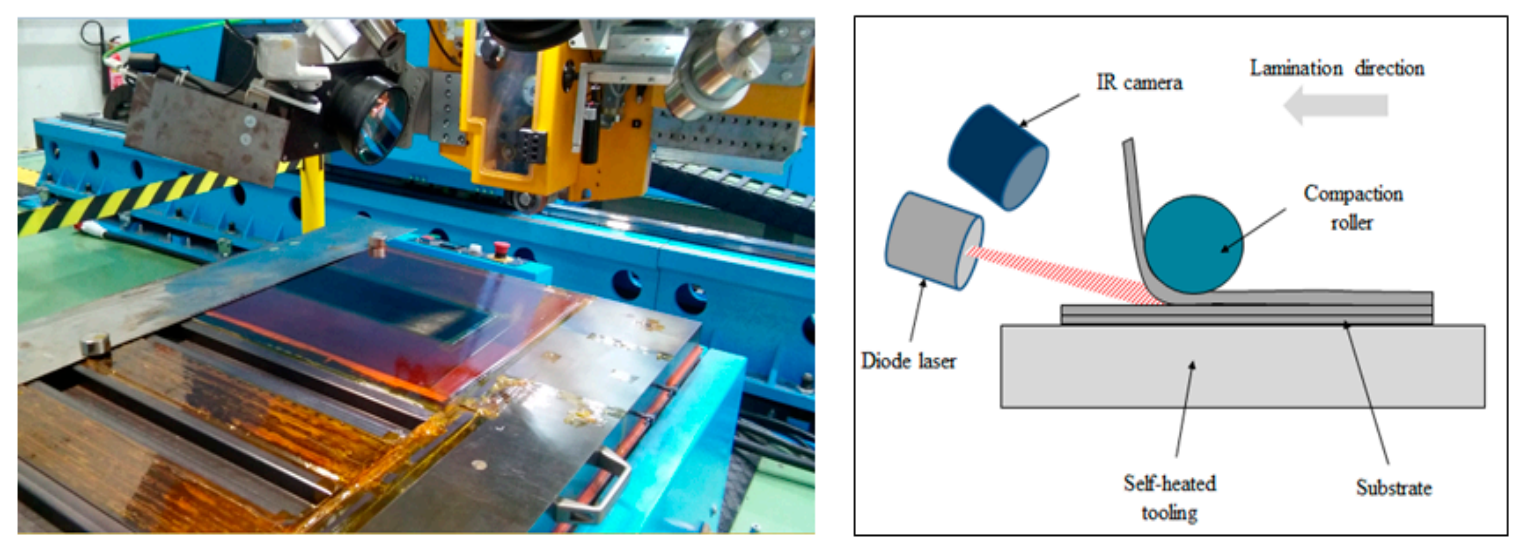

Figure 2. In-situ consolidation equipment in FIDAMC (Foundation for the Research, Development and Application of Composite Materials) (left); and a schematic diagram of the manufacturing process including manufacturing tooling, compaction roller, a diode laser, and an infrared thermographic camera (right).

Although semi-crystalline thermoplastic materials are used in most of the references on automatic lamination and in-situ consolidation, because these materials offer the highest performances, the process does not present any restriction to the layup with amorphous thermoplastic materials. Dai described 
in [22] the application of this process to the layup of carbon fiber and polyetherimide with revolution geometry.

In 2016, the first study where the application of this manufacturing process to the layup of flax fibers with polypropylene polymer was conducted [23]. A little later [24], results on flax fiber-reinforced polyamide layup were published. Such articles demonstrate the possible application of this manufacturing process to materials reinforced with natural fibers.

The critical aspect of productivity, a need for transfer of this process to an industrial scale, has been considered by different authors addressing different aspects. Among them, the reduction of the prohibitively high prices of materials [25] and of the auxiliary elements has helped to promote it as an alternative to consider in its application to the production of aeronautical parts.

Regarding the characteristics and the physics of the process of the layup, Khan et al. did a quite complete analysis on how different conditions/aspects of layup affect the level of porosity and the degree of joining between the layers and the relationship with the processing speed [26]. The following list contains its main conclusions. It can be seen that the improvements of some of the conditions normally have a negative impact on others, wherein the special complexity of this manufacturing process lies.

- Tooling temperature. The trend in void volume to decrease with lower layup speed is reversed when tool temperatures approach the melting temperature of the polymer included in the tape. When the temperature is low, the tool usually acts as a heat sink, leading to a high viscosity that prevents good movement of the chains and impacting a low degree of bonding, making it necessary to decrease the wrapping speed. In contrast, when the tool is at a high temperature (around $573 \mathrm{~K}$ for PEEK), good degrees of bonding are obtained even close to $10 \mathrm{~m} / \mathrm{min}$.

- Compaction force. The degree of bonding increases with higher contact forces, as should be expected, and the void content also declines. Its effect being more marked with the increase in the speed of the layup (the more speed, the more force required). Regarding the layup speed, the level of porosity should decrease with increasing force and increase in speed. On the other hand, the degree of bonding, despite increasing with force, decreases with speed.

- Number of layers. When the number of layers of a laminate is high, a double effect occurs; the lower ones receive more consolidation stages (reconsolidation) but the upper ones are more isolated from the heat sink-tooling. This causes them to experience greater heating and therefore it contributes to increasing the size of the pores.

- Heating length. Longer heating lengths contribute to increasing the level of porosity. On the other hand, the degree of bonding is improved, and the process can be carried out at higher speeds. Heating length is directly related to the heating time as both are related through the speed of lamination.

- The use of several rollers contributes to improving the degree of bonding, which can go from varying between $20-95 \%$ to a range between $70-95 \%$. Despite the advantage of having several rollers over compaction, increasing their number has a detrimental effect on the layup machine, making it necessary to have more components (more occupied volume) and making layup of complex geometries nearly impossible.

Despite all the problems present in this manufacturing system, parts of relative complexity have already been executed using this technology. Some of them are: Helicopter landing gear $[27,28]$, tail cone of a helicopter [29], rocket engine covers [30], cryogenic space tanks [31], and wingboxes [32,33].

In the manufacture of the wingbox, stiffeners designed with a closed omega geometry have also been implemented with automatic lamination and in-situ consolidation. To facilitate this development, tools made of metal alloys were used, whose melting point is $75{ }^{\circ} \mathrm{C}$ under the glass transition temperature of PEEK, thus facilitating their extraction by fusion once the layup has been completed. 


\section{Improvements to the ISC Process}

There are several sources of process distortion that are localized and whose improvement/resolution would imply, among other aspects, improving productivity. The layup and fastening of the first layer is one of them. Bibliographic solutions include tapes on unreinforced polymer sheets [34], tools with vacuum application or fixation adhesives [25,35], or employment of microporous tools [9].

The improvements to the process are not limited to physical components of the machine, control systems, or considerations of the layup; the material object of the lamination also has a dominant role in the results [36]. Based on the aforementioned statement, many works conclude that the results could be better with improvements on the quality of the taped material [22]. Other characteristics to be evaluated are [37]: Surface roughness, viscosity, and distribution of fiber and resin.

Another problem that is also extensible to any manufacturing process with composite material is the appearance of residual stresses [38-40]. Its development is inherent in the differences in the coefficients of thermal expansion between fiber and resin, but also the large thermal excursions of this process pose a greater problem. The layup process has another associated penalizing element, the sequential increase of layers of the material, leaving the material in an unfavorable state from the point of view of stresses. The residual stresses are not the same if the laminate cools evenly, as happens in autoclave, instead of a consolidation layer-by-layer. The residual stresses can become large enough to cause micro-cracks in the resin, and annealing over $\mathrm{Tg}$ may lower the residual stress gradients through the thickness of the laminate. An analysis was done by Sonmez et al. [41], where they propose certain ideas to reduce these thermal residual stresses:

- Pre-heating the incoming tape, in order to achieve a progressive drop in temperature when the tape and substrate come into contact, resulting in more progressive cooling and therefore reducing residual stresses.

- Working with a higher wrapping speed increases the residual stresses. The cause is the existence of point zones that are experiencing higher thermal gradients.

- The size of the heated surface also influences the residual stresses. The smaller the heated surface, the sharper the heating-cooling profiles. Better results are observed when the heated surface of the substrate is larger than that of the contribution.

August et al. [42] indicated that the need to use low layup speeds comes from a misinterpretation of De Gennes' theory of reptation; as the material enters the region of shear thinning the viscosity is reduced and therefore the time for chain relaxation is lower. In fact, Automatic Dynamics, producer of machines associated with the work of the cited reference, indicates that there is a real the possibility of producing pieces with this technology, indicating that they produce parts equivalent to $5000 \mathrm{~kg}$ of material each year using this technology.

From the work of Hoang [35], it was deduced how the effect of interlayer porosities is eliminated by the successive passes of the machine in the placement of the subsequent material. However, the last three layers are the most affected, indicating that three passes on the material are not sufficient to achieve the perfect bonding, with a wrapping speed of $1.5 \mathrm{~m} / \mathrm{min}$ and with heating provided by a hot gas torch. Furthermore, in that work it is argued that, according to the layup sequence, the need for reconsolidation passes is different, with different requirements for panels where all the layers are $0^{\circ}$ or $+/-45^{\circ}$. The problem is solved with reconsolidation passes without the input of material from a different number of layers depending on the sequence being taped. In some laminates, cooling systems are used when their thickness is such that the entire bottom laminate can act as an insulator with respect to the tool surface and generate an overheating effect. The above improvement is meaningless when active control systems are capable of acting on the power supplied by the heating source.

The compaction roller is also presented as an element of improvement for the process. Some authors are in favor of working with heated rollers (mainly proposed when they are metallic), while others propose solutions in which the roller requires cooling systems that avoid excessive deterioration of the constituent rubber (elastomers or silicones). The proposals for roller cooling systems are usually based 
on the fact that compaction must coincide with the solidification stage of the material to avoid the development of porosity in the laminates. The roller also plays a relevant role in the surface finishing of the part. In [30] the surface finishing results obtained with different cooling solutions for the roller were presented (by external air jet, by thermal contact against a cooled roller, or by flow of internal water) with cooling by internal water being the preferred solution.

\section{Thermal Transfer and Temperature Measurements}

In the processing of polymeric composite materials, either thermosets or thermoplastics, the applied thermal profile strongly influences the results for the obtained part. In the particular case of thermoplastic materials, by exhibiting a behavior that is dependent and not stable with temperature, it is of great interest to know precisely the thermal history to which the material is subjected. More particularly, for the automatic layup and in-situ consolidation process, the applied thermal profile will determine the development of changes in the material such as melting, chain diffusion, crystallization, the possible thermal degradation and the development of residual stresses.

\subsection{Heating Systems}

The heating system in the wrapping machines is one of the most questioned elements in the references, as reported [43-46]. Initially, the system was based on the use of hot gas torches, later evolving to the use of lasers, starting with $\mathrm{CO}_{2}$ lasers, going through the Nd:YAGs, and reaching the laser diode as the best alternative. This diversity of solutions for heating have been implemented with different results: Infrared sources have not reached the high intensity demanded by the heating to the nip point, while the hot gas torch manifests a low energetic efficiency and slowness in its response time, despite its low cost and design flexibility. The laser has turned out to be the first option based on its good energy efficiency and speed of response. Furthermore, in the case of lasers, for deciding on the use of one source or another it is vital to know the interaction with the material, especially the ability of the material to absorb radiation. In the case of $\mathrm{CO}_{2}$ type lasers $(\lambda=10,600 \mathrm{~nm})$, the resin shows a high absorbance; on the other hand, in the Nd:YAG and diode lasers $(\lambda=1064$ and 805-940-980 nm respectively), the resin is transparent to radiation, transmitting and reflecting all energy.

Regarding heating, in certain references the possibility using two sources of heating instead of a single one is alluded to. Tierney and Gillespie [47] indicates that the existence of a pre-heating system does not seek consolidation but a first effect of adhesion between the parts, helping to avoid harmful effects derived from cutting the material (lack of tension in the positioned tape, misalignment of fibers, etc.). The possibility of achieving this improvement is also reported in $[48,49]$, with a machine structure where there is only one laser-type thermal source and two roller-type compaction systems.

Many machines carry lasers with two groups of laser diodes at wavelengths $\lambda=975 \pm 10 \mathrm{~nm}$ and two others with $\lambda=1025 \pm 10 \mathrm{~nm}$ [50-52]. The incorporation of the diode laser type NIR (near-infrared) has allowed working with greater focal lengths than the carbon dioxide laser sources, from $127 \mathrm{~mm}$ to $250 \mathrm{~mm}$.

The diode laser is the most commonly used solution; Köhler et al. [53] mentioned a possible disadvantage of using this type of system, the lack of a homogeneous intensity distribution. The use of homogenizers can mitigate this effect, carrying out the homogenization by means of different alternatives. One of them is the superposition of beams of the laser itself; another system consists of incorporating a waveguide equipment. This can also be done by using a set of micro-optical lenses [54].

The use of $\mathrm{CO}_{2}$ lasers is shown as an alternative for heating uncolored surfaces as polymers without reinforcement or with glass fiber reinforcement [55]. The proposed solution has a direct application to fixing first layer problems or the use of sheets as functionalized surfaces, as well as in the development of hybrid components.

Currently, there are also machines where alternative heating systems are being tested, such as an ultrasonic heating source [56,57]. Ultrasonic heating consists of excitation and friction of the polymer molecules due to the low amplitude and high frequency of vibration of the ultrasonic waves. 
The advantages of using ultrasound heating sources are the focused heating, reducing the amount of energy required, allowing the increase of the welding speed. Its use has allowed automatic layup with polyethylene materials and glass fiber and polyethylene terephthalate with carbon fiber, but gives lower results than those obtained by press processing of the same material.

Lichtinger [58] reported the use of a different heating system, quartz lamps that apply infrared heating, developed by Heraeus Noblelight. The main disadvantage of this system is the need to be located almost in contact with the substrate and newly incoming tape.

Another alternative system referenced in several studies is the vertical-cavity surface-emitting laser (VCSEL) [59]. This system, made up of an array of microlenses, allows control of independent lines of the laser emission power. Among the advantages of using systems of this type are possible differential heating to join surfaces of different materials, compensation of areas with heat loss/areas with heat accumulation (homogenize the heating footprint), control of temperature distributions in complex tapes (curvatures) or control of the cooling profiles. Considering complex areas such as changes in curvatures or ramps, the effects that occur usually correspond to overheating, related to the laser position with respect to the laminate, where irradiation results from a relationship between the power supplied and the surface being irradiated. The decrease in the surface generates a higher irradiation for the same applied power level.

The advantages of VCSELs also have direct applications to the effects of under-heating at the laser inputs or possible overheating experienced at the outputs. In contrast, this system does not homogenize the laser beam, making it necessary to position it very close to the layup area and hindering the positioning of temperature reading and control systems.

\subsection{Heat Transfer Models}

With the aim of being able to control the automatic lamination and in-situ consolidation process, many research groups have tried to simulate the evolution of the thermal profiles in the heated material under the action of various thermal sources [60-80].

The first studies in this regard date from the 1980s, with the work of Grove [60] that uses the finite element method to solve the thermal transfer problem in APC2 with a two-dimensional simplification of geometry of the heating process using a laser source. However, experimental validation of the obtained results was not reported.

Some of the works also show the coupling of the thermal model with others, such as consolidation or degradation, in order to determine the optimal processing conditions, such as [64,66]. Sonmez [64] highlight the benefits of pre-heating the substrate and not the incoming tape to optimize the degree of bonding. The distribution between percent of heating in incoming tape and substrate is also discussed in [46], determining a high and stable value of peel strength between layers when the distribution of the area of heating is 60-incoming tape/40-substrate; they also recognize the need to run the tapes of the last layers at a lower speed to compensate for the reduction in consolidation times.

Toso [66] solved the problem of heating with a hot gas torch on laminate to obtain a geometry of revolution. He used a cylindrical coordinate system in the substrate material and a Cartesian system in the incoming tape. In this study, the contribution of heat flows from the crystallization exotherm and the fusion endotherm were neglected based on experimental results obtained by calorimetry. Their analysis determine that an over-estimate of the temperature values occurred when considering these effects, an over-estimate that was increased with the real cooling profiles of the manufacturing process.

Contrary to what was hypothesized previously by [66], in the case of modeling a similar thermal problem in thermoset materials, Hassan [80] takes into account the curing of the exotherm in the model as an added heat source. In his work, he modeled the added plies by adding new elements to the meshing at each iteration step. Nicodeau [81] carried out the modeling of the thermal problem with APC2 including in the equations the terms related to the melting and crystallization of the material. The problem is solved numerically with a two-dimensional geometric simplification. In order to account for the effect of depositing new layers of material, the elements of the interfaces are acted 
upon, modifying their boundary conditions: Before the actuation of the roller they will be isolated elements from each other and after the passage of the roller, equal temperatures will be imposed between these elements but not equal heat flow. It is worth noting in this reference the simplification of the tooling, which will be taken into account in the simulation as a boundary condition and not as a physical element, thus impacting calculation times. This simplification is also carried out in other references and hence different values for tooling are incorporated, which are also used in cases where it is estimated that there is no perfect material-tooling contact.

Ghasemi Nejhad et al. [62] performed an inter-comparison for solving the thermal problem using a numerical solution based on finite elements and also applying an analytical solution by means of a development based on variable separation. In his work it was shown that there is a good agreement in the solutions reported by both calculation methodologies.

On the other hand, Pitchumani et al. [63], proposed to execute the layup process by using two heating sources. The first one is a system for preheating the material. Among the hypotheses elaborated in this work, the following stand out: The heat flow of the crystallization is neglected as it is much lower than the others involved in the process and the first source of heating exerts its effect on the upper surface of the incoming tape. The work uses the thermal model to feed its study on the degree of consolidation and the evolution of porosity in the laminate. It reported improvements in the degree of bonding with increases in the compaction force, with increases in the air temperature of the heating torch, with the incorporation of a compaction system between both heat sources and with subsequent forced cooling (by reducing porosity when compacting during solidification).

Belonging to the same research group as the authors mentioned in the previous paragraph, Tierney and Gillespie [47] developed a work in which the numerical simulation of the thermal model in an automatic lamination process and the mathematical model that applies to dynamics in the formation of voids are presented together. The formulation of its thermal model considers a simplification in a single dimension and under a steady state.

As shown above, several groups worked on dual heating sources to improve consolidation. With a similar purpose but a different architecture, Li et al. [82] alludes to the use of an infrared preheating system of the material fed by the machine. They proposed a simplified thermal model for this pre-heating effect, which allows estimation of the diminution in layup time due to pre-heating, related to the tape speed. Experimental validation was not done.

Regarding the heating system, Lee [44] presents the differences to be imposed in the thermal transfer equation in the analysis of a layup process with composite material, depending on what type of heating source is being used, such as heating with a hot gas, hot air, and with a solid element. In the case of heating with a hot fluid/liquid, it is estimated that the coefficient of thermal convection should be at least twice that considered when using a hot gas source. When heating with a solid element, the convection contour condition is replaced by a constant temperature condition in the interface between the element and part, this being the system that allows the shortest response times and also the one that offers the least risk to possible degradation effects on the material. The only disadvantage linked to this type of system is the need to generate them as heated rollers with a temperature control system.

Thermal simulations are run by using the FlexPDE software in $[83,84]$, including for the output heat losses of the material due to radiation. Thermal simulation allows explanations for variations in the mechanical properties of the fracture between test specimens manufactured with different holding times on the melting temperature of the polymer.

Other methodologies used in solving the thermal problem can be found in $[48,49,85-87]$, with the use of the numerical method called proper generalized decomposition (PGD), which solves the heat equation by variables separation and with a methodology based on the application of the principle of virtual works. Likewise, in these works the effect of the thermal resistance between layers (also used by Grouve, [71]) is accounted for. Taking into account that there is no perfect contact between the layers for heat transmission, it generates more precise results of the temperature profile experienced by 
the material, especially improving the precision of the adjustment in the cooling phase. The resistivity condition between the layers acts in such a way that it considers that there is a blockage to the heat transmission to the lower layers and therefore the cooling is more impeded and is therefore more progressive. In other studies, by contrast, this effect is considered negligible for simulation [88].

In some works [48], a correlation between heat transmission and the mechanisms of diffusion and degradation by cross-linking in the material is also presented (without considering the effect of intimate contact, assuming perfect contact), reporting a beneficial effect by keeping the tool heated at a temperature of $473 \mathrm{~K}$, a condition in which $100 \%$ adhesion is obtained with a minimum cross-link value. Normally, the tooling temperature should be kept at a value between the glass transition and crystallization peak of the material. In the case of a material such as PEEK, PEKK, or LMPAEK (well-known as high performance thermoplastics), $473 \mathrm{~K}$ is a conventional temperature that has proven to improve the quality of the final part.

Appling a layup process with an electromagnetic inductor-type heating source, Duhovic et al. [72] presented a resolution of the thermal model using the finite element method. His study highlights the possibility of executing hybrid metal-carbon composite or -carbon fiber composite joints against another counterpart using an intermediate susceptor. The special feature of this simulation was the need to add cooling on the upper surface to avoid its excessive heating, because the objective was to join an interface far away from this surface area. The simulation has also made it possible to reach conclusions regarding the correct adhesion of the elements, indicating that to achieve a correct joint, the compaction step must take place in the temperature range of $653 \mathrm{~K}$ to $553 \mathrm{~K}$, since it corresponds to the interval in which the re-crystallization/solidification of the polymer takes place.

In the model of Li et al. [74] the novelty lies in the methodology used to simulate the sequential addition of layers to the laminate in a layup with a hot gas torch. The strategy is based on the programming of an algorithm in ANSYS that gradually activates the elements with the evolution of the layup. It does not mean that the elements of the model appear and disappear, but rather they are multiplied by certain factors so that during the layup of layer 1, the highest layers do not have influence on the model; their contribution appears upon reaching the layup to them and so on. Among his hypotheses, it is worth highlighting they ignore the effect of heat dissipation towards the roller, a simplification not carried out by most of the works consulted. In one of his conclusions it was indicated that increasing the layup speed decreases the temperature in the nip point, presenting a trend that is not linear between both parameters.

Contrary to neglecting the roller as a participant in the simulation, Kergomard, [76], proposes the development of a mechanical simulation that allows calculation of the deformation of the roller under the state of loads to which it is subjected, then evaluation of the thermal model. In this way, less uncertainty is generated about the area of the roller's action in the thermal model.

The thermal study carried out by Stokes-Griffin et al. [51,89,90] alludes to an effect penalizing heating in automatic lamination compared to heating obtained by filament winding; the shadow of the roller is an effect to be included in simulations. Due to the positions that each of the elements must occupy in the machine head and the deformation of the elastomeric rollers, a reduced area is generated where the laser is not capable of heating, a few millimeters before the contact of the incoming tape with the substrate (nip point). The experimental validations as well as the models show a temperature drop in this shadowed region, greater for the substrate than for the incoming tape due to the greater heat losses at the substrate. The author of the work indicates that said shadow effect affects the subsequent consolidation area (started from the nip point) and therefore, each machine will be subjected to very different results only due to differences in this simple element of the machine. In its development, the roller is counted as a physical body, including its geometry in the finite element model applied to solve the heat equation, unlike the vast majority of previous references where the roller is considered a boundary condition. The condition that applies between roller and laminate is a thermal conduction condition which includes the possibility of considering a thermal resistance effect; the higher this thermal resistance, the less the heat sink effect of the roller. The value that best adjusts 
the roller-laminate thermal resistance in this investigation corresponds to: $1-2\left[\mathrm{~m}^{2} \mathrm{~K} / \mathrm{kW}\right]$, a typical value in stainless steel-silicone interactions.

In the thermal model proposal of the previous reference, velocity terms are included in the left-hand side of the heat equation, which is not normally considered, to include the effect of mass transport of heat due to moving elements, proposing Equation (1).

$$
\rho c\left(\frac{\partial T}{\partial t}+v_{x} \frac{\partial T}{\partial x}+v_{y} \frac{\partial T}{\partial y}\right)=\ddot{q}+\frac{\partial}{\partial x}\left(K_{x} \frac{\partial T}{\partial x}\right)+\frac{\partial}{\partial y}\left(K_{y} \frac{\partial T}{\partial y}\right)
$$

Furthermore, this study analyzes the need for mesh reinforcement for the validity of the simulation. To do this, it reports thermal diffusivity values of the different components of the modeled geometry, using this parameter to calculate the Peclet number, which establishes the limit of the size of the mesh elements. Because of the results, a greater number of elements are required in the area of the roller directly in contact with the laminated material.

In $[69,89]$ the effect of the multiple passes experienced by a layer of material on the final result of the laminates is considered. Ref. [69] considers that approximately two layers below the layup area the material is still melted, while several more layers experience temperatures between the glass transition and the melting (considering layup speeds of 1.2 to $4.8 \mathrm{~m} / \mathrm{min}$ ). This effect implies, according to the authors, an increase in the degree of contact between the parts that evolve from 0.75 to 0.9 in the joint line after only three layup passes, thus making it necessary to re-consolidate the upper layers to obtain a homogeneous laminate. Ref. [89] reports that at speeds of 6 and $24 \mathrm{~m} / \mathrm{min}$ with AS4/PEEK150. Only the layer that is being laminated with the $673 \mathrm{~K}$ set point undergoes fusion, the bonding processes being conditioned by these thermal profiles.

The same author of the previous article published a study [91] with a new methodology that seeks to obtain the requirements of heat flow on the laminate by imposing the temperature that is desired to govern the interface region. In this way, the power that would be required for that specific result can be estimated. The work highlights the statements made on the "heat soak", which is described by the author as the time the material is kept at the set temperature; when the "heat soak" value is reduced, the material spends less time at the maximum temperature and the cooling profiles are slower, which positively affects crystallization.

Pignon et al. [92] couples the contribution of the heat flow generated by the crystallization of the material in an injection molding process to the thermal model. They apply the Nakamura model for the crystallization process.

Di Francesco et al. [34], proposed an analytical and a semi-empirical approach of the thermal problem, applied to a machine able to tape thermoplastic and dry fiber prepreg. An equation is presented in his work to estimate the temperature of the nip point, as a function of the layup speed $(V)$, the power $(P)$, material parameters $(K)$, and the machine set-up $(K)$ (heating footprint), showing a linear trend with the variation of power (Equation (2)). Some deviations from linearity happen due to the dependency of the material properties and the temperature, but experimental errors are lower than $10 \%$, so its validity is demonstrated. Its development has allowed establishment of an open control loop to adjust the parameters of power-speed-temperature of lamination.

$$
T_{V N P}=K V^{-0.5} P+T_{0}
$$

Weiler et al. [77] proposed an analytical resolution of the thermal Equation (1) considering that it is the most effective/fastest method to establish online control of the automatic layup and in-situ consolidation. Numerical solutions used to be more accurate, but less flexible and more time consuming than analytical solutions, which require some simplifications in the problem statement, in order to be solved. Among the novel hypotheses and considerations that appear in this work are those listed below:

- The thermal resistance to heating of the laser source is determined to be of infinitely small value, hence the advantage of this type of heating over others. 
- The temperature-dependent properties of the material are simplified using its average value in the temperature range considered.

- Even executing an analysis of the layup process of a curved geometry, the author proposes to simplify the material as a plate geometry.

- The depth of penetration of the laser is considered to be less than the depth of penetration of the heat flux.

The validity of these hypotheses has been proven by comparison of the analytical predictions with the numerical results for eight different cases. The article proposes two control models for the process, one based on an open loop system (a system that is not based on any external reading but on previously calculated solutions) and another a closed-loop system (using readings on the back of the fed material obtained with pyrometers).

The power supplied by the source will be included in the models as a heat flow estimated from the value of the power in $(\mathrm{W})$ and its application area.

For the correct operation of the simulations presented by the different authors, feeding with the values of the different thermal properties of the material is required, properties that in the case of composite materials are anisotropic and in many cases are also dependent on the temperature. To shed more light in this regard, Table 1 contains a compilation of the bibliographic values of different parameters required for thermal modeling together with the information provided on the material under study.

Table 1. Thermal properties of the poly-ether-ether-ketone (PEEK)-carbon fiber (CF) composite.

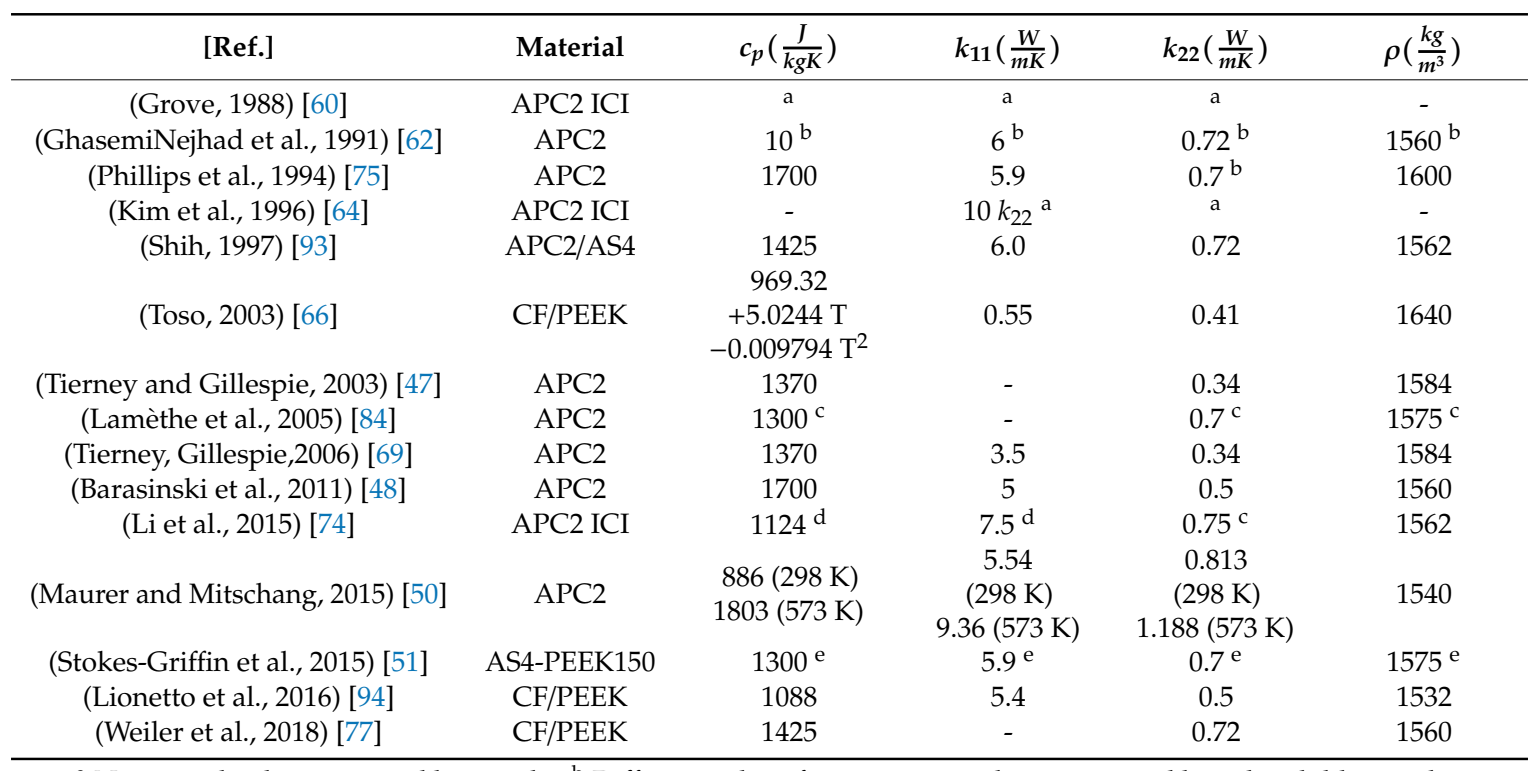

a Numerical values reported by graphs; ${ }^{\mathrm{b}}$ Different values for process window were used based on bibliography;

${ }^{c}$ Values for $473 \mathrm{~K}$, check reference for 523, 573, 623, $673 \mathrm{~K}$; ${ }^{\mathrm{d}}$ Values for $453 \mathrm{~K}$, check reference for others; ${ }^{\mathrm{e}}$ Values for $473 \mathrm{~K}$, check reference for others.

It is also possible to locate some work [95] where the thermal properties of the fiber and the resin are presented independently, allowing estimation of the validity of the law of mixtures, useful for other fiber/resin systems when laminate properties are not available. The reported values for PEEK and carbon fiber (T300) are, respectively, conductivity of $0.25 \mathrm{~W} /(\mathrm{mK})$ and $50 \mathrm{~W} /(\mathrm{mK})$. Densities of $1.32 \mathrm{~g} / \mathrm{cm}^{3}$ and $1.85 \mathrm{~g} / \mathrm{cm}^{3}$ and specific heat $320 \mathrm{~J} /(\mathrm{kg} \mathrm{K})$ and $710 \mathrm{~J} /(\mathrm{kg} \mathrm{K})$. The law of mixtures may work for the density, but fails for the anisotropic thermal conductivities.

In the simulation, not only will the material's own parameters intervene, but also the transmission of heat to the environment, by the tooling or by the compaction roller; this requires feeding the model 
with a set of numerical values. In the case of the tooling used for lamination, it is possible to find a variety of parameters according to the references; Table 2 includes some of them.

Table 2. Thermal properties for the tooling.

\begin{tabular}{ccccc}
\hline [Ref.] & Tooling Material & $c_{p}\left(\frac{J}{k g K}\right)$ & $k\left(\frac{W}{m K}\right)$ & $\rho\left(\frac{k g}{m^{3}}\right)$ \\
\hline (Ghasemi Nejhad, 1991) [62] & Steel & 473 & 43 & 7800 \\
(Stokes-Griffin et al., 2015) [51] & Aluminum & 951 & 237.5 & 2689 \\
\hline
\end{tabular}

The remaining thermal transfers will be modeled based on boundary conditions. The parameters that apply have been reported by references and are compiled in Table 3.

Table 3. Thermal properties for boundary conditions.

\begin{tabular}{cccc}
\hline [Ref.] & Roller Material & $\boldsymbol{h}_{\text {Roller }}\left(\frac{W}{m^{2} K}\right)$ & $h_{\text {Air }}\left(\frac{W}{m^{2} K}\right)$ \\
\hline (Grove, 1988) [60] & - & 500 & 7 \\
(Nicodeau, 2005) [81] & Metal & 1000 & 13 \\
(Stokes-Griffin et al., 2015) [51] & Elastomer & 1000 & $5-17.1$ \\
\hline
\end{tabular}

In the simulations, the results are totally linked to the layup speed considered (which will condition the heating time, among others), hence it is of interest to know the values reported in the different works, which have been collected in Table 4.

Table 4. Layup speeds for PEEK-carbon fiber and other thermoplastics in in-situ lamination and consolidation processes.

\begin{tabular}{cc}
\hline [Ref.] & Lamination Speed (m/min) \\
\hline (Grove, 1988) [60] & 6 \\
(Ghasemi Nejhad et al., 1991) [62] & $0.6-6$ \\
(Kim et al., 1996) [64] & $2.4-3.6-4.8$ \\
(Sonmez y Hahn, 1997) [65] & 1.8 \\
(Pistor et al., 1999) [79] & 0.9 \\
(Tumkor et al., 2001) [67] & 2.4 \\
(Toso, 2003) [66] & 6 \\
(Tierney y Gillespie, 2003) [47] & 2.4 \\
(Nicodeau, 2005) [81] & $1.2-2.28-4.2^{\text {a }}$ \\
(Grouve, 2012) [71] & $4.5-6-7.5^{\mathrm{b}}$ \\
(Han et al., 2014) [73] & $0.3-1.5^{\mathrm{c}}$ \\
(Maurer y Mitschang, 2015) [50] & $3-6-12^{2}$ \\
(Stokes-Griffin et al., 2015) [51] & 8 \\
(Stokes-Griffin y Compston, 2015) [89] & $6-24$ \\
(Weiler et al., 2016b) [78] & 12 \\
(Lionetto et al., 2016) [94] & $0,06-0,24^{\mathrm{d}}$ \\
(Di Francesco et al., 2017) [34] & $6-12-24-48$ \\
(Weiler et al., 2018) [77] & 0 to 30 \\
(Murray et al., 2017) [31] & 12 \\
\hline (M)
\end{tabular}

Recent simulations, based on systems with laser heating sources, take into account the optical behavior of the material for the calculations. In the above cases, it is key to know the optical properties of the materials, which are compiled in Table 5. To obtain the reflectance and transmittance of a thin material, experimental measurements can be carried out using a spectrophotometer; later, 
by using mathematical expressions, the reflection index value (real and complex components) can be obtained [96].

Table 5. Optical properties of the PEEK-CF composite material.

\begin{tabular}{|c|c|c|c|c|c|}
\hline [Ref.] & Reflectance & Absorbance & Emissivity & $\begin{array}{c}\text { Refraction } \\
\text { Index } \\
\text { (n)-Material }\end{array}$ & $\begin{array}{l}\text { Refraction } \\
\text { Index } \\
\text { (n)-Roller }\end{array}$ \\
\hline (Grove, 1988) [60] & 0.28 & - & - & - & - \\
\hline (Grouve, 2012) [71] & - & - & 0.9 & 1.8 & - \\
\hline $\begin{array}{l}\text { (Stokes-Griffin and } \\
\text { Compston, 2015) [51] }\end{array}$ & - & - & - & $1.95-2.30^{\mathrm{a}}$ & 1.42 \\
\hline $\begin{array}{c}\text { (DiFrancesco et al., } \\
\text { 2017) [34] }\end{array}$ & - & $0.6^{\mathrm{b}}$ & $0.8^{c}$ & - & - \\
\hline (Weiler et al., 2018) [77] & - & 1 & 0.9 & - & - \\
\hline (Reichardt et al., 2018) [97] & - & - & - & - & 1.4 \\
\hline
\end{tabular}

Some of the works that take into account the optical behavior of the material in their simulations are $[51,71]$ with a two-dimensional or 3D ray tracing approximation, respectively. In these works, it is stated that the use of the ray tracing approach to describe the behavior of the material is justified because the diameter of the carbon fibers is an order of magnitude greater than the working wavelength of the laser.

Ref. [51] performs thermo-optical modeling based on the result of the optical model under the hypothesis of a micro half cylinder (MHC), a divergent emitting source and a spatial emittance function. In the work, he performs intercomparisons with different methodologies of representation both of the surface of the material (specular, non-specular, or MHC) and of the irradiation system. He also incorporates an analysis of the variations in the thermal profiles caused by the differences in the orientation of the fiber of the substrate material, observing that its effect can be considered negligible.

Schaefer et al. [88] uses a thermo-optical model in the layup with carbon fiber reinforced polyamide (CF/PA-6); they establish a laser source term depending on the absorbance of the material which is in turn dependent on the angle of incidence of the laser. Reichardt et al. [97] developed a three-dimensional model considering non-specular reflection.

The references agree on the identification of the PEEK polymer as a material where the main behavior against laser radiation is transmission (both in an amorphous and semi-crystalline state). For its part, the carbon fiber acts as a highly absorbent element in which the reflected radiation depends on the orientation of the fibers in relation to the radiant focus.

When a laser irradiates a material, the energy is absorbed, transmitted, or reflected, and the percentage for each of these contributions directly affects the properties of the material, and also affects its crystalline or amorphous state. Due to the participation of the properties of the material, some studies are dedicated to its determination and the estimation of its dependencies with respect to different factors, for example the temperature (Ref. [71] for the CF/PPS, Ref. [51] for the CF/PEEK, and Ref. [88] for CF/PA-6). Among the results obtained for the CF/PEEK the following conclusions stand out.

- The crystalline phases scatter light by local variations of the refractive index. The detection of higher absorbance in a semicrystalline material compared to an amorphous one is associated with the subsequent reception of the reflected rays. In the case of the composite material, the limited thickness of the surface resin layer and the small size of the spherulites formed make these points of reflection limited and can be considered negligible.

- The behavior of reflection of the PEEK in the NIR (near-infrared) can be considered representative of that presented by this material under laser radiation. 
- The refractive index of the resin is estimated to be dependent on temperature inversely to the dependence of the coefficient of thermal expansion.

- The optical properties of the carbon fiber can be considered constant in the range of temperatures experienced during the in-situ consolidation and lamination process.

- Radiance is considered to be proportional to the irradiance in this material.

- The transmittance can be considered negligible for the CF/PEEK. The polymer, which in the amorphous state would have a high transmittance of laser energy, being reinforced by the fiber, would have a negligible effect on the whole. Transmittance can be neglected in calculations.

- In the composite material, the reflection depends on the orientation of the fiber with respect to the emitting focus, showing special reflection patterns.

- Knowing the angle of incidence of the laser, it is possible to estimate the angle of reflection by applying Snell's law.

- It can be estimated that most of the incident light is both absorbed and reflected by the first carbon fiber layer of the surface and this allows the analysis to be simplified to a surface to run models of macroscopic behavior.

- It is possible to consider the refractive index in the composite material only for its real part as there is practically no absorption.

- In radiation simulation, choosing a collimated beam with the geometry of a hat-shaped profile is not appropriate when working with NIR lasers with the inclinations required by the ISC process; it is essential to consider the beam divergence.

- After two beam reflections, the irradiation intensity becomes negligible. To realistically model heat transfer, the laser incidence profile should also account for these first two reflections.

Once the optical model is developed, the next step is to perform its coupling with the thermal model. In the bibliography, the importance of elaborating these thermo-optical simulations is highlighted due to the underestimation that conventional thermal models make of the real energy required by the material for heating, since they do not take into account the reflectance of the material. Weiler et al. [78] compiled information from different works where the previous statement is supported, but also from others, where it is indicated that the laser radiation impacts on the substrate and incoming tape, which are reflected from each other and, therefore, leave a final balance in which there is no loss or energy gain. The author presents a variation in absorbance and reflectance depending on the angle of incidence of the heating source where it can be seen that once the incidence angles of $60^{\circ}$ have been exceeded, the reflectance begins to be important, estimating that its impact on radiant exposure (integration in time of radiation exposure) is approximately $16 \%$.

Referring to the thermo-optical coupling, Grouve [71] did his model under the assumption that the speed of heat conduction in the forward direction of the layup is much lower than the displacement of the machine. Under these conditions, the process is governed by conduction through thickness, proposing a methodology for solving the energy balance based on a pseudospectral or placement method. Also, Reichardt et al. [97] coupled their optical and thermal models, with the special characteristic of describing the reaction of the material to radiation with a micro-model, the reflections obtained from its application are extrapolated to the macro- model.

To take into account the orientations of the reflected rays, Reichardt et al. [97] uses a bidirectional reflectance distribution function, solving the thermo-optical problem numerically. It is also the first work we identified where the problem was solved in an analytical way, comparing the results of the application of both methodologies. The numerical and analytical results are very similar when specular reflection of light is taken into account in the numerical solution.

Weiler et al. [78] proposed an optical model for a VCSEL heating source. The work carries out a first view on the generalities of laser heating and the requirements to simulate it by considering the distribution of angular intensity, irradiance, and absorbed intensity, but leaving the depth of penetration of the laser out of the study. In the simulation, a calculation is carried out to consider the 
superposition of the effect of the independent lamps constituting the VCSEL, demonstrating that the irradiation decays towards the nip point in the substrate and increases towards the nip point in the incoming tape.

A model with simpler optical considerations is the one proposed by Maurer and Mitschang [50], the first document in which COMSOL Multiphysics software was used. This model in turn uses two sub-routines programmed in MATLAB for the heating source and for the roller. The laser model estimates the power applied to the substrate and input material. Since the system is focused, it is modeled considering the height of the focal point and the focal distance to the nip point. In addition, the laser beam has its own coordinate system that allows it to vary its position in the model, then change the substrate-incoming tape temperature distributions. The incident heat flow in the material comes from a calculation that takes into account absorption and reflection (considering the same angle for incidence and reflection).

For its part, the roller model is used to approximate the contact length by simplifying its geometry by means of a rectangular area (contact with the substrate) and another trapezoidal area (drop area of the incoming tape). The simulated roller takes into account the cooling system built with the roller.

Lionetto et al. [94] also uses COMSOL Multiphysics to run a thermal model of a process with heating with an ultrasound source. Moving mesh is used for simulation, an element made possible by the characteristics of the software. The heat equation to be solved incorporates a term that accounts for the endotherm corresponding to the heat absorbed during the melting process of the material polypropylene/E-glass. The same research group also developed a work where heating was carried out using a source of induction on CF/PEEK [98], re-accounting the melt heat flow (Equation (3)) and incorporating a term corresponding to crystallization (Equation (4)). This last term was obtained by means of the Ozawa equation, with $\mathrm{Cr}$ being the relative crystallinity, whose relationship with temperature and time is described as indicated by Equation (5). The Ozawa equation is not the most suitable representation to describe crystallization in PEEK under dynamic conditions, because it does not take into account the secondary crystallization, but still may be used to estimate the enthalpic effects.

$$
\begin{gathered}
X_{m}(T)=\left[1+(d-1) \exp \left(k_{m b}\left(T-T_{C}\right)\right)\right]^{\frac{1}{1-d}} \\
X_{C}=C_{r}\left[0.42-0.03 \ln \left(\frac{d T}{d t}\right)\right] \\
\log \left[-\ln \left(1-C_{r}\right)\right]=\log (\exp [-0.037 \cdot \mathrm{T}+11.3])+n \log \left(\frac{d T}{d t}\right)
\end{gathered}
$$

Besides those works where only the heat transfer model is analyzed, there are other works where multi-model couplings with all the possible physics involved in this process are analyzed together (thermal-bonding-crystallization-degradation) [71,81].

\subsection{Experimental Determination of Temperature}

As this manufacturing process is carried out, it is necessary to know the laminate temperatures in real time to act operatively by varying the intensity supplied by the heating source based on those readings. The equipment used for this purpose usually reports temperature values by non-contact measurements on the area under action of the heating source. The roller pressure application area is hidden from the non-contact reading, thus losing all the information on the cooling profile. Speed for the cooling profiles and the successive stages of reheating in the environment at $200 \mathrm{~K} / \mathrm{s}$ are reported [60]. This is one of the motivations for carrying out the simulations. Likewise, executing experimental measures with various systems contributes to extracting this information and evaluating whether the simulations developed are close to the actual results.

The methodologies used to monitor the temperature and analyze the validity of the simulation results are different depending on the document consulted. They are usually based 
on thermocouple-type temperature probe readings as reported in $[48,51,61,64,70,80,81,88,93]$, pyrometers [63], or thermal imaging cameras [71].

In verifying the thermocouple readings of the thermal profiles, there are several references that discard the results of the first tapes on the thermocouple. The ruling out of these measures is based on the unfavorable effects of direct laser irradiation on the thermocouple [88], which can be surrounded by air after the first tapes on it. As the layup evolves, the thermocouple embedding improves, making the data more rigorous. The simulations may later serve to complement the information of those measurements that were considered unreliable.

Seeking to correct this negative effect of the measurement, [51] analyzed the temperature recorded by the thermocouple at a location. Taking a point at the same distance from the nip point as the thermocouple, the differences between the thermography and thermocouple reading were estimated. These differences were used to propose a correction of the temperature value of the thermocouple, which was applied to understanding what happens in areas where thermography cannot be used as a measurement system.

In relation to the control through a thermography camera, the former authors [89] established the polluting effect of the reflections of the material being taped on the thermal reading in the substrate material. This causes the readings on the thermal imager to be higher than the real values presented by the laminate.

Taking into account the positions of the incoming tape and substrate, the bibliography indicates the impossibility of monitoring the temperature for both in the same way. The substrate may support thermocouple monitoring; however, the incoming tape is limited to thermography measurements.

Oromiehie and Saenz del Castillo $[98,99]$ demonstrated a system to monitor temperatures in manufacturing systems with thermoplastic composite materials by the use of Fiber Bragg Grating sensors (FBG). The basic principle of FBGs lies in engraving a small section of an optical fiber in such a way that the core refractive index is periodically modulated using an optical interference pattern, allowing it to receive a response in reflection. Under certain conditions, the response obtained presents a peak centered on a different wavelength from the initial one recorded on the sensor. This effect is related to an external effect such as the application of a mechanical load or a thermal load.

Saenz del Castillo et al. have compiled in [100] the equations for thermal analysis, and the results for predicted and measured temperatures are presented in Figures 3 and 4, compared with a real experiment monitored by FBG with good agreement.

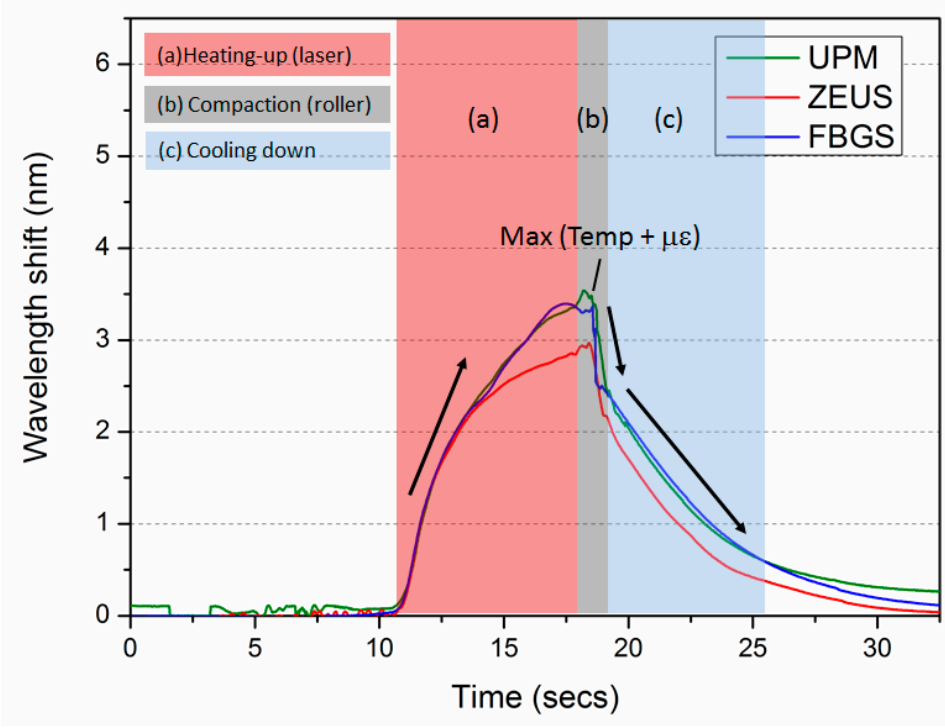

Figure 3. Wavelength shift monitored by sensors UPM, ZEUS and Fiber Bragg Grating sensors (FBGs) during the in-situ consolidation of a single CF/PEEK layer. Three different stages can be identified: Heating-up by the laser (a), effect of the compaction roller (b), and cooling down (c). 


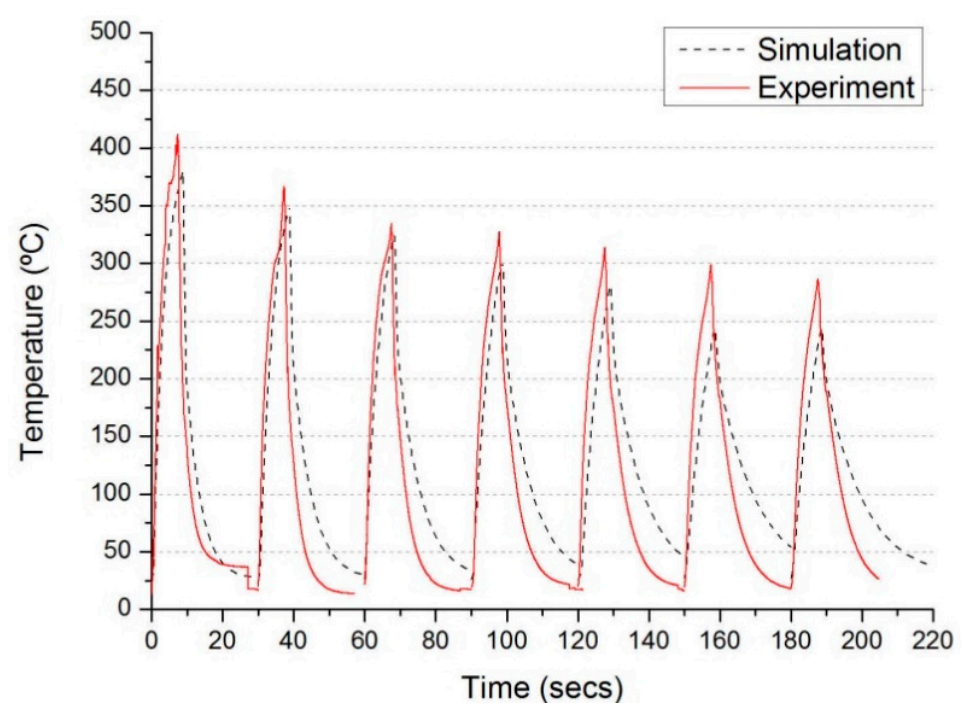

Figure 4. Comparison of thermal profiles provided by FBG process monitoring and thermal model simulation.

\subsection{Control Systems}

Thermal models determine the temperatures experienced by any point of the laminate during the layup process. Another objective for the development of the model is to enable control over the wrapping equipment, seeking that it can autonomously carry out modifications to the power signal sent by the laser and that it is simultaneously capable of extracting information about the consolidation states, crystallinity, residual stress, or degradation effects.

Obtaining information on what happens in lower layers than the positioned one allows establishment of a possible quality status in the piece; however, for active control it seems logical that the system uses a fundamental criterion for the control the adhesion requirements of the layer to be taped at that specific moment. Khan [101] highlights the problem of applying a control by means of a PID (proportional-integral-derivative system) due to the slow response of this system to changes in the profile, with deviations of up to $15 \mathrm{~K}$ from the set point temperature. To compensate for this problem, he proposed two solutions based on two different methodologies within control theory: The optimal quadratic control strategy and the predictive control model (MPC).

In the optimal quadratic control system, the determination of a law for a control vector is pursued; a linear quadratic regulator (LQR) is used, which receives measurements from external sources such as pyrometers, accompanied by a linear quadratic estimator (LQE), a Kalman filter, to predict uncertainties in areas where it is not possible to extract values of measurements. The combination of both is carried out by means of a Gaussian quadratic linear control (LQG). The strong point of the predictive control model (MPC) is the combination of control algorithms together with the modeling of the process for predicting the response. The responses by both control systems (LQG and MPC) are similar except when certain restrictions are taken into account in the MPC. These restrictions can be limitations of the types: Maximum value of power that the heating system can supply or maximum value of temperature that can be reached during the process.

Heider et al. [68], on the other hand, based its control system on the use of a neural network. The system is used to control the values of the machine parameters, looking for those that lead to the most optimal manufacturing solution. According to the authors, this control system shows the best response capabilities as compared to a traditional proportional-integral-derivative (PID) system. 


\section{Adhesion}

In the analysis of the adhesion mechanism between the layers of the composite material, the process must be described taking into account two factors: On one hand, the elimination of surface roughness in the incoming material to allow the displacement of the polymer chains and, on the other hand, the mechanism that controls this movement of chains.

\subsection{Intimate Contact Theory}

Between two surfaces of thermoplastic pre-impregnated composite materials brought into contact, without the application of pressure or temperature, there are gaps due to the inherent irregularity of the surfaces of the material. The high viscosity values of thermoplastic resins mean that they have a limited ability to cover these areas only by natural flow of the polymer, making it necessary to force the contact of both surfaces by physical means (application of pressure). In order to account for the effect of this contact and the evolution of the destruction of the irregularities, models of "intimate contact" emerge, the starting point of which is to characterize the surface state of the material.

It should be pointed out that the time required to achieve contact between the surfaces will increase the greater the irregularity carried by the material, hence the importance of characterizing and controlling this effect, whose impact on the productivity of the process is decisive.

\subsubsection{Representation of the Material Surfaces}

The starting point for modeling the removal of roughness in the material is to know its initial state. In the bibliography, it is possible to locate different references where models of representation of the material are included, taking into account different geometric approximations of its surface. Woo Il Lee and Springer [19] proposed to model the surface of these materials as a succession of identical rectangles. On the other hand, Loos and Dara [102] used a histogram of heights measured on the surface of the material to represent its irregularity using a Weibull-type distribution function.

Pitchumani et al. [63] used a surface model of rectangles. In this work, the temperature and pressure profiles developed in the automatic layup process were used to evaluate the evolution of the roughness state of the material, unlike values used by other works where average estimated values in temperature were used.

Yang and Pitchumani [103-106] proposed a representation using fractal surfaces, a model also used in $[107,108]$ that lead to Equation (6). This approach is based on proposing that the surface irregularity exists on different scales. In [107] the need for re-consolidation passes on the material to achieve high values of intimate contact is analyzed. The work concluded that at least three reconsolidation passes are required without material input to achieve $100 \%$ degree of contact.

$$
D_{i c}^{n}(t)=\frac{1}{f^{n}}\left[\frac{5}{4}\left(\frac{h_{r}}{L_{r}}\right)^{2} \frac{f^{\frac{2 n D}{2-D}+n+4}}{(f+1]^{2}} \int_{t_{n+1}}^{t} \frac{P_{a p p}}{\mu_{m f}} d t+1\right]^{1 / 5}
$$

Equation (6) is the one used for the evolution of the degree of intimate contact. $D$ is the fractal dimension, $f$ the scaling factor, $n$ the number of irregularities, $L_{r}$ the total length to establish the Cantor set, Papp the applied pressure, $t$ the duration of pressure of the roller, $\eta_{m f}$ the viscosity of the compound, and $h_{r}$ the depth break of the first generation of irregularities found. A summary of the mentioned surface representation methodologies is presented in [109]. The authors carry out the application of the models of identical rectangles and fractal surfaces for the analysis of the degree of intimate contact in polyamide (PA6) reinforced with carbon fiber. Regarding the application of fractal models, it is indicated that with them it is possible to obtain the parameters required by the model by means of simple profilometric measurements, an important fact compared to models that use rectangles as they are supported by approximations with mathematical adjustments. In return, these models are not 
always applicable to any material and after their use they show an underestimation of the degree of real intimate contact between the two parts.

In [52] the experimental determination of the degree of contact was obtained from the analysis of the areas with and without deconsolidation in the interfaces of the different layers of the material. Levy et al. [110] used an optimization algorithm to extract the roughness parameters based on the results under specific processing conditions.

In Perez et al. [111] the surface of the material is represented by means of multi-level elements. The authors carry out a comparison of the evolution of the degree of intimate contact over time in the automatic layup and in-situ consolidation starting from different surface finishes of the material and under the action of different laser powers. In all the results, the material with the most stable roughness is presented as the one that requires the shortest time to reach $100 \%$ of the degree of contact.

Similar developments were also applied to thermoset material [112]. In the case of these materials, as it happened with thermoplastics, the temperature, the viscosity, the compaction force, and the layup speed are the parameters that impact the result.

\subsubsection{Evolution of the Surface Irregularity}

Considering an initial distribution of identical rectangles on the surface of the material, with height $a_{0}$, width $b_{0}$, and separation between them $w_{0},[19]$ uses the volume conservation equation, Equation (7), as tool to analyze the evolution of intimate contact on the surfaces of the material once the crushing takes place.

$$
V_{0}=a_{0} b_{0}=a b
$$

As a definition for the degree of intimate contact between two surfaces, the relationship between the final width of the irregularity or rectangle $(b)$ over the sum of the initial width $\left(b_{0}\right)$ plus the initial rectangle spacing is established $\left(w_{0}\right)$. In addition, taking into account the conservation of volume, we reach Equation (8).

$$
D_{i c}=\frac{b}{w_{0}+b_{0}}=\frac{\frac{a_{0}}{a}}{1+\frac{b_{0}}{w_{0}}}
$$

By applying the conservation of mass equations to a control volume, assuming laminar flow, executing algebraic simplifications and estimating the force to be exerted in the unit area, the equation that predicts the evolution of the degree of intimate contact as a function of time, temperature, pressure, and surface finish of the material is Equation (9).

$$
D_{i c}=\frac{1}{w_{0}+b_{0}}\left[1+\frac{5 P_{a p p}}{\mu_{m f}}\left(1+\frac{b_{0}}{w_{0}}\right)\left(\frac{a_{0}}{b_{0}}\right)^{2} t\right]^{1 / 5}
$$

Considering that the total degree of contact is reached when $D_{i c}=1$, it is possible to calculate the time needed to attain it as shown in Equation (10):

$$
t_{i c}=\frac{\mu_{m f}}{5 P_{a p p}} \frac{1}{1+\frac{w_{0}}{b_{0}}}\left(\frac{b_{0}}{a_{0}}\right)^{2}\left[\left(1+\frac{w_{0}}{b_{0}}\right)^{5}-1\right]
$$

When the process conditions are non-isothermal, the integral expression to analyze the evolution of the degree of intimate contact is given by Equation (11) [66].

$$
D_{i c}=\frac{1}{1+\frac{w_{0}}{b_{0}}}\left[1+5\left(1+\frac{b_{0}}{w_{0}}\right)\left(\frac{a_{0}}{b_{0}}\right)^{2} \int_{0}^{t} \frac{P_{a p p}}{\mu_{m f}} d t\right]
$$


The expression shown in [63] appears simplified as Equation (12).

$$
D_{i c}=a^{*}\left[\int_{0}^{t_{b}} \frac{P_{a p p}}{\mu_{m f}} d t\right]
$$

Adopting a $a^{*}$ value of 0.29 in the case of APC2/AS4.

As can be inferred from the previous equations, the calculation requires knowledge of the viscosity of the fiber-resin composite material. The surface of this material is primarily polymer. The viscosity is determined as the value obtained from the zero shear rate at different temperatures, assuming that the cutting speed does not intervene in the automatic layup process.

In the case of APC2/AS4 material, Table 6 shows the equations from different bibliography sources. The matrix-fiber viscosities were obtained by measuring the thickness change of samples when compressed at different temperatures in the interval of interest (340-400 ${ }^{\circ} \mathrm{C}$ for PEEK), for a given compaction force and time (details are given in [107]) then adjusting the values to an Arrhenius kinetics. Significant differences happen among these equations, suggesting a strong dependence on the tape characteristics.

Table 6. Definition of bibliographic parameters for the intimate contact degree equations.

\begin{tabular}{ccc}
\hline [Ref.] & $\mu_{m}[$ Pa.s $]$ & $\mu_{m f}[$ Pa.s $]$ \\
\hline Woo Il Lee, Springer 1987 [19] & $1.13 \cdot 10^{-10}\left[\exp \left(\frac{19100}{T}\right)\right]$ & $1.14 \cdot 10^{-12}\left[\exp \left(\frac{26300}{T}\right)\right]$ \\
(Marchello, Messier, 1996) [113] & PEEK 150P & $132.95\left[\exp \left(\frac{2969}{T}\right)\right]$ \\
(Mantell, Springer, 1992) [114] & $1.13 \cdot 10^{-10}\left[\exp \left(\frac{19100}{T}\right)\right]$ & $132.95\left[\exp \left(\frac{2969}{T}\right)\right]$ \\
(Sonmez, Hahn, 1997) [65] & - & $643\left[\exp \left(\frac{4367}{T}\right)\right]$ \\
(Khan, Schledjewski, 2009) [107] & - & \\
\hline
\end{tabular}

\subsection{Polymeric Chain Movement Theories of Self-Adherence}

When two polymeric surfaces come into contact with each other, their temperature over their glass transition, a diffusion of the polymer chains occurs in the interface, commonly known as healing, diffusion, or self-adhesion. In the development of a resistant joint, a correct diffusion of the chains must be developed so that the interface can become indistinguishable.

The basic theory for explaining the mechanism of chain diffusion at the interface is De Gennes' theory of reptation $[115,116]$. A description of this theory is beyond the scope of this article; it can be found elsewhere [117].

Moving now towards the adhesion mechanism between two surfaces of material during automatic layup and considering chain reptation, it is necessary to take into account the movement of the well-known minor chains [118]. Initially, a chain is surrounded entirely by a tube (topological restrictions). For a time $t 1$, the chain begins to leave the tube, mainly at the ends, and those initial portions that have evacuated the tube are called minor chains. The length of the chain leaving the tube $1(t)$ is an increasing function over time; this magnitude will be the main control mechanism in the development of the binding resistance.

Depending on the capacity of interpenetration of the polymer chain in the face of the material, it is possible to develop a more or less resistant bonding, which is a direct cause of the mechanical behavior of the joint.

The relationship of diffusion/healing is directly alluded to the mechanical properties developed by the interface of the material, presenting the following dependencies for resistance and energy of fracture with time $[104,118]$ (Equation (13)) and the estimation of the value of the degree of diffusion (Equation (14)).

$$
\frac{\sigma}{\sigma_{\infty}}=\left(\frac{t}{t_{r}}\right)^{1 / 4} ; \frac{G_{I c}}{G_{I c \infty}}=\left(\frac{t}{t_{r}}\right)^{1 / 4}
$$




$$
D_{h}=\frac{\sigma}{\sigma_{\infty}}=\frac{\chi}{\chi_{\infty}}=\left(\frac{l}{L}\right)^{1 / 2}
$$

Likewise, those references establish a relationship between the lengths (minor chain and fully evacuated chain) with the temperature holding times, only in isothermal conditions, with the relationship represented by Equation (15).

$$
\frac{l}{L}=\left(\frac{t}{t_{r}}\right)^{1 / 2}
$$

Combining the above equations, for the case of isothermal conditions the degree of healing can be expressed as indicated in Equation (16), as a function of the holding time of the process conditions and the polymer reptation time.

$$
D_{h}=\left(\frac{t}{t_{r}}\right)^{1 / 4}
$$

The equation may be reformulated by dividing the thermal history into infinite intervals to take into account the possible non-isothermal conditions of the process [65]. In this way Equation (17) is obtained. The integration of the previous expression leads to Equation (18) for calculating the degree of self-adherence.

$$
\begin{gathered}
\frac{d l}{L}=\frac{d t}{2 \sqrt{\eta t_{r}(\eta)}} \\
D_{h}=D_{a u}=\frac{S}{S_{\infty}}=\left(\int_{0}^{t} \frac{d \eta}{2 \sqrt{\eta t_{r}(\eta)}}\right)^{1 / 2}
\end{gathered}
$$

An experimental verification of the healing value achieved in APC2/AS4 is carried out using a mechanical tensile test between two parts joined under different thermal cycles in a press [19]. After the temperature stabilization, the specimens are quenched in cold water. Based on the degree of healing obtained, the authors are able to provide a relationship of dependency with time and temperature, as shown in Equation (19). Note that the higher the temperature, the less time required to reach $100 \%$ of the degree of self-adhesion. It is important to note here that the models used by the reference are valid in the case of amorphous materials, hence the quenching of the samples.

$$
D_{h}=44.1 \cdot \exp \left(\frac{3810}{T}\right) t_{a}^{1 / 4}
$$

Pitchumani et al. [63] on the other hand, did use the models proposed by Bastien and Gillespie [118] for the PEEK-based composite materials, estimating the degree of healing achieved by Equation (20) when the process takes place in non-isothermal conditions.

$$
D_{h}\left(\tau_{h}\right)=\left(\frac{1}{t_{r}^{*}}\right)^{\frac{1}{4}} \sum_{j=1}^{\frac{\tau_{h}}{\Delta \tau}} \frac{\tau_{j}^{1 / 4}-\tau_{j-1}^{1 / 4}}{a_{T} T_{j}^{1 / 4}}
$$

With:

$$
a_{T}=\exp \left(\left(\frac{E_{a}}{R}\right)\left(\frac{1}{T}-\frac{1}{T_{r e f}}\right)\right)
$$

The parameters of the equation adopt the following numerical values in the reference cited: $E a=57.3 \mathrm{~kJ} / \mathrm{mol}$ and $\left(t_{r}\right)=0.11 \mathrm{~s}$ for the reference temperature $673 \mathrm{~K}$.

More recent works $[26,107]$ use the mathematical integral relation of Equation (23) to extract the degree of healing through its dependence on the welding time. This equation had already been used by Yang and Pitchumani $[104,106]$ in their statistical analysis. Welding time is extracted for the greatest molecular relaxation of the molten polymer and at a specific test temperature. The greatest relaxation is found in the change from the linear to the non-linear regime in the curves obtained from a dynamic 
rheology test. Likewise, they propose a solution for the evolution of that time with temperature based on an Arrhenius-type dependency relationship with PEEK 150 PF (Equation (22)).

$$
\begin{gathered}
t_{w}(T)=2 \cdot 10^{-5} \exp \left(\frac{43000}{R T}\right) \\
D_{h}=\left(\int_{0}^{t} \frac{1}{t_{w}}\right)^{1 / 4}
\end{gathered}
$$

\subsection{Bonding Theory}

Once the degrees of intimate contact and diffusion have been obtained, it is possible to combine their results to obtain information on the general degree of bonding.

In the work of Pitchumani et al., 1996, it is indicated that during automatic layup with thermoplastic reinforced material, the available times for intimate contact are much shorter than those of chain reptation or diffusion (since this mechanism it does not need an associated pressure to take place), therefore it can evolve as long as the temperature does not freeze the movement of the chains and allows the following simplification to be made for the degree of bonding (Equation (24)). Experimentally, there seems to be a good correlation between the obtained degree of bonding values and the resistance values of the test specimens to "short beam shear" (SBS).

$$
D_{b}\left(\tau_{b}\right) \approx D_{h}\left(\tau_{h}\right) \cdot D_{i c}\left(\tau_{i c}\right)
$$

Sonmez and Akbulut [119] presented a complete algorithm to locate the best parameters in the layup with thermoplastic material and to do it they analyzed the degree of bonding by means of Equation (25), which is a convolution of the degrees of contact and diffusion.

$$
D_{b}\left(t_{b}\right)=\int_{0}^{t_{b}}\left[\int_{0}^{t_{b}-\tau} \frac{d \eta}{\sqrt{\eta t_{r}(\eta)}}\right] \cdot \frac{d D_{i c}}{d \tau} d \tau
$$

Nicodeau [81] compiled models by various authors and clarified that the application of some of them is restricted to amorphous thermoplastic polymers. In the case of semi-crystalline polymers, not only does it present a different behavior, but it also clarifies that not reaching a perfect fusion in the material generates a crystal remnant in the set that prevents free movement of the chains. It also incorporates one more element into the study that gives an idea of the complexity of the process with semi-crystalline materials, the adhesion and formation of a crystalline interface, and the effect of co-crystallization, which makes the fracture mechanism very complex. The experimental determination of the relaxation times is carried out using rheology tests and attending to different criteria: With the time provided by the Carreau model in the change of tenure between the Newtonian regime and shear thinning, with the time of the crossing of the slopes of $G^{\prime}$ and $G^{\prime \prime}$ when the frequency of the dynamic test tends to zero, and with the longest time of the relaxation spectrum.

Tierney and Gillespie [69] analyzed the development of intimate contact as a function of the layup passes and the lamination speed. Their results show that with very high layup speeds, increasing the consolidation passes does not impact the degree of contact but, on the other hand, it increases with the passes when the speed decreases. They also detect that approximating the distance between the hot gas torch and the laminate increases the value obtained from the degree of intimate contact.

In a recent study [57], which performed the layup with glass fiber reinforced polypropylene, the equations previously exposed were also used to analyze the degree of self-injury and intimate contact. Its purpose is to determine the minimum times necessary to reach the total degree of bonding, highlighting the importance of the viscosity of the material in estimating this time.

Among the limitations of these models are, on the one hand, the analysis of the consolidation in the first stage between two layers of material, which is the evolutionary process, and the involvement 
of the bond of multiple layers impacting time after time on the lower ones. Zhao et al. [120] presents a work that tries to cover this problem, presenting an equation for the analysis of the pressure on the nth layer and the relationship of the degree of contact with the evolution of the layup. The work is carried out under the assumption that viscosity of the composite material can be approximated by that of the resin, since this is the most superficial component of the ply.

The times described above for both intimate contact and diffusion or healing can be high if extrapolated to the industrial application of the automatic layup and consolidation process in situ, as they result in very high conservative values.

\section{Crystallization}

Crystallization is probably one of the most important topics for polymer science. It is out of the scope of this review to attempt to summarize the state-of-the-art methods. We just included some works dealing with specific aspects of crystallization during ISC and its consequences on mechanical properties. It is worth mentioning that, when cooled from melt, some thermoplastic polymers such as PEEK can arrange in a partially ordered crystalline structure, called lamellae, about 10-20 nm thick and formed by folding the polymer chain. In a bulk polymer these lamellae grow radially from a nucleation point, creating spherical crystalline regions called spherulites. In the presence of fibers, new phenomena appear.

\subsection{Transcrystallization}

Transcrystallization consists of a process of crystal growth affected by restricted space. Interfacial crystallization, or transcrystallization, offers a new possibility to improve the interaction between the polymer and the reinforcement in a composite material. The reinforcement acts as a nucleus that induces crystal growth, as occurs with PEEK on carbon fiber reinforcements. The presence of the reinforcement forces growth to take place in a direction perpendicular to the surface of the fibers, until the crystals collide with those generated in the bulk [121].

This crystalline formation has a fundamental impact on the mechanical behavior of the material. In the case of longitudinal properties, an improvement is reported with the interaction of the trans-crystalline layer, since the matrix in the direction of the fiber has greater strength and stiffness and its thermal expansion is reduced, which directly impacts on the residual stresses. Transversally, an example is reported for glass fiber reinforced polyamide, where there is a maximum in the tensile strength and in the modulus for cases where slow cooling leads to better transcrystalline layers. More information regarding the effect of this layer on mechanical properties is included in the section on the relationship between mechanical properties and crystallization.

There are several studies that analyze the crystallization phenomenon in the PEEK polymer and in the PEEK thermoplastic matrix composite materials, for the particular process of automatic layup and in-situ consolidation [122,123].

\subsection{Crystallization and Mechanical Properties}

Despite the fact that there are numerous effects conditioning the final mechanical behavior of parts manufactured with composite materials of thermoplastic matrixes (porosity, residual stresses, etc.), crystallization is one of the most highlighted factors in the references consulted as a key element in the development of some mechanical or other properties [124-127]. Its findings are linked to the thermal profiles to which the part was subjected. The references analyze the impact of the crystallinity percentage, such as the impact of the crystal morphology and the mechanical property under analysis.

The impact of the crystallinity of the polymer on the mechanical properties requires independent presentation for the net and reinforced polymer. In the composite material, the contribution of the fiber as a nucleating agent and the impact of the transcrystalline layer on the result under different mechanical stresses must be considered. 


\subsubsection{Crystallization and Mechanical Properties in PEEK}

Cebe et al. [128] analyzed the mechanical behavior affected by crystallinity for the net PEEK polymer, using tensile tests on samples that were, respectively: Abruptly cooled to obtain an amorphous state, crystallized from the amorphous state, and crystallized at fast and slow speeds from the melt. In addition, the tests were run at three different temperatures below the glass transition. The samples crystallized in the conditions of slow cooling from the melt, and in all test cases a zone of plastic behavior with the lowest values of deformation at break and resistance to final failure was present.

\subsubsection{Crystallization and Mechanical Properties in Composite Material}

Lee et al. [129] analyzed glass fiber and polypropylene composite materials under different cooling profiles, drawing conclusions against different states of mechanical stress. In unidirectional traction, the highest value is obtained in the case of lower cooling speed due to the good adhesion achieved between resin and fiber. On the other hand, in a fracture (mode I, mode II and mixed), interlaminar shear (ILSS), and impact, the behavior improves at a higher cooling rate. However, it should be emphasized here that the tests were carried out with cooling programs at 1, 10, and $20 \mathrm{~K} / \mathrm{min}$, with ranges very close to each other and not very representative of the large values observed in automatic lamination and consolidation in-situ.

One of the causes for the variations in mechanical properties is the correct or incorrect development of the transcrystalline layer during cooling of the material [130]. This work draws different conclusions about the effects of applying different "annealing" conditions on samples with polyamide 6 and polyamide 6 with continuous reinforcements of carbon fiber. Among their conclusions, they mentioned an increased thermal conductivity with crystallization since it is a property that depends on the vibration of the structure of the crystalline lattice.

Gao and Kim $[130,131]$ show a correlation between crystallinity and properties such as interfacial shear strength (IFSS) or short beam shear (SBS). According to their analysis, there is a marked difference between specimens that have undergone cooling at $1 \mathrm{~K} / \mathrm{min}$ over those that have undergone cooling at $600 \mathrm{~K} / \mathrm{min}$, reflecting a decrease both in mechanical properties and in the measured value of crystallinity by calorimetry. The study of the fracture gap also shows a cohesive behavior when cooling was slow and a cohesive-adhesive (matrix-open) behavior when cooling was abrupt. These same authors extended their investigations to the analysis of the effect of crystallinity on the interlaminar fracture toughness in laminates with PEEK and carbon fiber [132]. In mode I, the conclusions were that the crack propagation is more stable as the cooling rate increases, as a cause of the plastic behavior of the resin in the peel gap. Likewise, for greater cooling speeds, the crack length is also shorter for a given opening displacement. In both failure modes, I and II, the energy decays with increasing crystallinity, which is equivalent to increases in energy with increasing cooling speed; however, these increases are not as high as when the net resin was subjected to these cooling profiles. Possible causes for differences in toughness with the resin are associated with the non-plastic behavior of the fiber and also the weak fiber-resin interface generated in rapid cooling. A third extension of the work [133] analyzes the relationship between crystallinity and impact damage behavior in samples crystallized in the range of 1 to $80 \mathrm{~K} / \mathrm{min}$. According to the tests carried out, laminates with a lower crystalline percentage (higher cooling speed and smaller spherulite size) are characterized by being more ductile and having a greater capacity to resist the onset of delamination and absorption of impact energy.

These findings were in agreement with those presented by D. Ray et al. [134]. They found that mode I fracture toughness is $60-80 \%$ higher for the LATP (laser assisted tape placement) processed specimens than for the autoclave processed specimens. The higher fracture toughness of the LATP processed specimens is partially due to significant plastic deformation in the interior of plies during the DCB (Duble Cantilever Beam) test, because of the lower crystallinity.

Not every mechanical property was improved. Regarding the tensile and flexural behavior and the effect of crystallinity on these properties, Gao et al. published a study [135] where the results for transverse and longitudinal specimens were shown. Except for the longitudinal traction, influenced by 
the fiber, the other tests showed a decreasing trend with the decrease in crystallinity, and the flexural properties were much more affected. The samples that underwent rapid cooling contained a matrix rich in amorphous phase, unable to bear the bending load, particularly the compression component. Furthermore, the authors reported a limit value on the cooling rate of $600 \mathrm{~K} / \mathrm{min}$, above which there were no variations in the results.

El Kadi and Denault [136] proposed to analyze the variation of mechanical properties, both static and fatigue, in laminates where the presence and absence of spherulites was confirmed. In this work they alluded to other bibliographic references where it was indicated that the variation in mechanical properties with rapid cooling is more associated with an increase in residual stresses than with the modifications of crystalline structure, as well as the possibility of obtaining similar crystallinity percentages with totally different crystal morphologies. In fatigue, there does not seem to be a significant effect of the characteristics of the matrix, but, on the other hand, in static conditions it does not occur in this way and the important effect of the fiber-matrix interface is again mentioned.

In line with the effect on the mechanical properties of crystallization, there is also an effect of crystallinity on the glass transition and on the enthalpic relationship, as proposed by Toft [137]. The crystal-amorphous interface is indicated to have a remarkable role in the response to thermal aging in the vicinity of the glass transition, detectable through enthalpic relaxation. Higher degrees of crystallinity imply a greater number of chains with restriction and therefore the need for higher temperatures to get those chains to move.

\section{Thermal Degradation}

The impact of thermal degradation on the consolidation of the material in its application to the automatic wrapping and in situ consolidation process was analyzed in [138], one of the first works to deal with this issue. The degradation analysis was carried out by analyzing the results of interlaminar shear strength (ILSS) in test specimens manufactured under different heating conditions. They concluded that there are two competing mechanisms governing laminate ILSS: Bonding among layers and degradation. At very high temperatures (laminates of PEKK were exposed for a short time to a gas torch with temperatures ranging 700-900 ${ }^{\circ} \mathrm{C}$ ) a degradation effect is induced in the polymer, creating voids at the surface, that cannot be compensated for in the successive passes and causing the strength values to drop. Microscopic examinations were also done. A higher void content was found at the two extremes of the temperature interval: At low temperatures because of poor bonding, and at high temperatures and long dwell times because of degradation. The former reference is purely empirical, and more insight was needed to address this issue; it can be found in the next set of references.

By definition, the thermal degradation of a polymer consists of a process such that, due to the action of heat or high temperature, an irreversible loss of physical, mechanical, or electrical properties occurs [139].

In the degradation process of a polymeric material, the long molecules are usually broken down into smaller segments capable of volatilization. The lighter the fragments, the greater their capacity to evaporate as soon as they are generated; meanwhile, the rest of the molecules will remain in the condensed phase (liquid or solid) and will continue to undergo decomposition until the fragments are appropriately sized. Some of the waste generated may remain in the form of carbonaceous residue, not volatilizing. The atmosphere in which the process takes place has an important role; when oxygen intervenes (oxidative atmosphere) it can produce changes both in the reaction rate and in the order of the reaction. It can also decrease the minimum temperature required for degradation.

The mechanisms that apply in the thermal decomposition of a polymer are:

- Random excision of chains. Breakage occurs at apparently random positions on the chain.

- Excision at the end of the chain. Individual monomer units are successively removed from the end of the chain. 
- Stripped from the chain. Atoms or groups thereof are broken which are not part of the backbone of the polymer.

- Crosslinking. Links between chains of the polymer are formed.

For manufacturing processes where it is required to raise the temperature of the polymers approaching their degradation, it is important to analyze their thermal resistance. Hancox [140] did a review on the main decomposition mechanisms of polymeric materials. In the particular case of PEEK, the reference indicates that for a material with an aromatic structure, its reaction to thermal degradation is more stable than other polymers. The work indicates that the degradation of the first $1-2 \%$ in the material takes place by means of an autocatalytic mechanism.

The works of Nicodeau [81] and Patel et al. [141] analyze the possible products obtained in the degradation process in PEEK. The first of the works make hypotheses about the two possible routes in which material degradation is expected to occur in an oxidative atmosphere. In the first hypothesis, degradation is considered to take place by breaking the constituent bonds of the polymer chain (breaking in ether or ketone bonds) and a second hypothesis is that the radicals that initiate the reaction come from peroxides that can exist in the polymer structure (possibly generated during the impregnation process of the material). Starting from the polymer, oxygen can act by removing the hydrogens from the $\mathrm{CH}$ aromatic bonds, leaving a structure with a free position to react, generating crosslinking and attraction between the different positions that have been left free in the chain.

The second of the works [141] studied the PEEK response to fire. In this work, the analysis carried out on how chain linkage breaks and recombines is highlighted. In the process, both in oxidative and inert atmospheres, there are two fundamental mechanisms where the presence of reinforcements such as carbon fiber provide stability by slowing down the degradation process. Contrary to what was reported by other works, the authors indicate that the process begins with the breaking of the carbonyl-ketone bond and continues with the breaking of the carbonyl-ether bond.

The previously referenced working group also presents a PEEK decomposition analysis using thermogravimetry [141]. The document alludes to the existence of two stages of degradation in the decomposition process of the polymer in an oxidative atmosphere. The first stage is based on the cleavage of the ether and ketone bonds and the second stage is associated with the oxidation of the carbonaceous residue. In the work, calorimetry tests were developed at different speeds. With these tests it is possible to observe that the first of the processes is not affected by speed, the same with the second, which has a marked dependence on speed. Furthermore, in the intercomparison between the oxidative and inert atmospheres they carry out, the behavior of the polymer reflects an early start of degradation for the oxidative case with a difference of about $100 \mathrm{~K}$ compared to the inert case; however, in the first stage of degradation in inert conditions there is a drop $10 \%$ higher than that of the oxidative case.

In line with these observations made on the thermogravimetry curves in PEEK, Ref. [142] shows the short temperature interval between the degradation of $5 \%$ by mass and the maximum degradation peak of the material (this interval being the equivalent of about $10 \mathrm{~K}$ ). This result shows that, despite this material having a high temperature of degradation, the speed at which it occurs is very high and once the appearance of volatiles has been generated, the evolution of polymer degradation is rapid.

The effects of degradation on samples subjected to short heating cycles are analyzed in the works of Bayerl et al. [143] and Tsotra et al. [144]. Ref. [143] conducted a study on the possible thermal degradation experienced by carbon fiber reinforced PEEK under the action of a laser-type heating source (wavelength $980 \mathrm{~nm}$ ) and temperature maintenance times of the millisecond order. The experimental techniques used for the analysis were differential scanning calorimetry, electron microscopy, and infrared spectroscopy by Fourier transform. Infrared spectroscopy lead to the conclusion that decomposition begins with the breakdown of the phenyl bond, the ether bond, and the aromatic hydrogen, with new peaks appearing that are the result of new associations of the cleaved chains. 
The behavior of GF/PP laminates manufactured by ISC consolidated with a $\mathrm{CO}_{2}$ laser is described in [145]. A good mechanical and micrographic characterization is given. Thermal degradation kinetics models and experimental characterization techniques are detailed in [146]. The analysis was applied to a carbon fiber/PEEK composite, and a good agreement among the predictions done by the kinetics analysis and degradation measured on samples submitted to laser irradiation was found. This paper is a good demonstration on how to combine experimental measurements and kinetic simulation to define the optimal processing conditions.

\section{Conclusions}

The in-situ consolidation process for manufacturing thermoplastic composites is a delicate balance among the high temperatures required for local melting and healing of the surfaces of the substrate and incoming tape, but avoiding the thermal degradation of the material. A compaction pressure is needed to ensure an intimate contact. The roughness of the tape has a strong influence on the final quality. The whole heating-cooling process takes a quite short time, about $10 \mathrm{~s}$, over a small, moving area. Higher taping speeds means shorter times and more difficulties. It is then understandable that, in spite of the potential benefits of these materials, the application of this process to large serial production is still under discussion. This article compiles the relevant literature, identifying some of the existing issues to be addressed and models being used.

Author Contributions: Conceptualization, A.G. and I.M.; methodology, A.G.; investigation, I.M.; resources, I.M., A.F., D.S.d.C.; writing—original draft preparation, I.M.; writing-review and editing, A.G.; visualization, A.F.; supervision, A.G. All authors have read and agreed to the published version of the manuscript.

Funding: This research is funded by the Institutions of the authors.

Conflicts of Interest: The authors declare no conflict of interest.

\section{References}

1. Dutton, S.; Kelly, D.; Baker, A. Composite Materials for Aircraft Structures, 2nd ed.; AIAA: Reston, VA, USA, 2004; ISBN 9781563475405/9781600861680.

2. Campbell, F.C. Manufacturing Processes for Advanced Composites; Elsevier: New York, NY, USA, 2004; ISBN 9781856174152.

3. Biron, M. Thermoplastic Composites. Thermoplastics and Thermoplastic Composites; Elsevier: New York, NY, USA, 2018; pp. 821-882, ISBN 9780081025017.

4. Hoa, S.V. Principles of the Manufacturing of Composite Materials; DEStech Publications: Lancaster, PA, USA, 2009; ISBN 9781932078268.

5. Segal, L.; Testa, A. Lamination of Highly Reinforced Thermoplastic Composites. U.S. Patent 4,469,543, 4 September 1984.

6. Brown, C.L.; Ashcraft, H.C.; Tichenor, D.R.; Garcia, R.M. Automated Tape Laminator Head for Thermoplastic Matrix Composite Material. U.S. Patent 4,990,213, 2 February 1991.

7. Holmes, S.; Lawton, S.A.; Haake, J.M. Method for Heating and Controlling Temperature of Composite Material during Automated Placement. U.S. Patent 6,451,152, 17 September 2002.

8. Maison, S.; Meunier, S.; Thibout, C.; Mouton, L.; Payen, H.; Vautey, P.; Coiffier-Colas, C.; Delbez, J. Method for Making Parts in Composite Material with Thermoplastic Matrix. U.S. Patent 6,613,258, 2 September 2003.

9. Burchell, P. Method of Tape Laying of Thermoplastic Composite Materials. U.S. Patent Application No. 12/922,923, 13 January 2011.

10. Zaffiro, P.A. Control of Radiant Heating System for Thermoplastic Composite Tape. U.S. Patent 5,177,340, 5 January 1993.

11. Hauber, D.E.; Langone, R.J.; Martin, J.P.; Miller, S.F.; Pasanen, M.J. Composite Tape Laying Aparatus and Method. U.S. Patent 7,063,118, 20 June 2006.

12. Martin, J.P. Multiple Tape Laying Apparatus and Method. U.S. Patent 7,293,590, 13 November 2007.

13. Langone, R.J.; Hauber, D.E.; August, Z.A. Thermoplastic Composite Prepreg for Automated Fiber Placement. U.S. Patent US20130164498A1, 27 June 2013. 
14. Langone, R.J.; Becker, R.D. Methods for Forming a Structure Having a Lightning Strike Protection. U.S. Patent 8,947,847, 3 February 2015.

15. Langone, R.J.; Hauber, D.E.; August, Z.A. Thermoplastic Composite Prepreg for Automated Fiber Placement. U.S. Patent US20160023433A1, 28 January 2016.

16. Cope, R.D.; Funck, S.B.; Gruber, M.B.; Lamontia, M.A.; Johnson, A.D. Tape Placement Head for applying Thermoplastic Tape to an Object. U.S. Patent 7,404,868, 29 July 2008.

17. Caffiau, J.; Gaillard, L.; Hardy, Y. Fiber Application Head including a Segmented Compaction Roller. U.S. Patent 9,248,591, 2 February 2016.

18. Martín Hernando, M.I. Modelización del Proceso de Laminación Automática y Consolidación In-Situ con Materiales Compuestos Termoplásticos APC2/AS4. Ph.D. Thesis, E.T.S. de Ingenieros Aeronáuticos (UPM), 2019. Available online: https://doi.org/10.20868/UPM.thesis.56804 (accessed on 22 August 2020).

19. Lee, W.I.; Springer, G.S. A Model of the Manufacturing Process of Thermoplastic Matrix Composites. J. Compos. Mater. 1987, 21, 1017-1055. [CrossRef]

20. Cogswell, F.N. Thermoplastic Aromatic Polymer Composites: A Study of the Structure, Processing and Properties of Carbon Fibre-Reinforced Poly-ether-ether-ketone and Related Materials; Elsevier: Amsterdam, The Netherlands, 2013; ISBN 9781483164762.

21. Kozaczuk, K. Automated Fiber Placement Systems Overview; Transactions of the Institute of Aviation: Warsaw, Poland, 2016; Volume 245, pp. 52-59. [CrossRef]

22. Dai, S.C.; Ye, L. Characteristics of CF/PEI tape winding process with on-line consolidation. Compos. Part A Appl. Sci. Manuf. 2002, 33, 1227-1238. [CrossRef]

23. Baley, C.; Kervoëlen, A.; Lan, M.; Cartié, D.; Le Duigou, A.; Bourmaud, A.; Davies, P. Flax/PP manufacture by automated fibre placement (AFP). Mater. Des. 2016, 94, 207-213. [CrossRef]

24. McGregor, O.; Duhovic, M.; Somashekar, A.; Bhattacharyya, D. Pre-impregnated natural fibre-thermoplastic composite tape manufacture using a novel process. Compos. Part A Appl. Sci. Manuf. 2017, 101, 59-71. [CrossRef]

25. Lefebure, P.; Lang, D. DINAMIT Development and INnovation for Advanced Manufacturing of Thermoplastics. In FP6 Aerospace European Project 2004-2007. Available online: cordis.europa.eu/project/id/ 502831 (accessed on 22 August 2020).

26. Khan, M.A.; Mitschang, P.; Schledjewski, R. Identification of some optimal parameters to achieve higher laminate quality through tape placement process. Adv. Polym. Technol. 2010, 29, 98-111. [CrossRef]

27. Derisi, B.; Hoa, S.V.; Xu, D.; Hojjati, M.; Fews, R. Mechanical behavior of carbon/PEKK thermoplastic composite tube under bending load. J. Thermoplast. Compos. Mater. 2011, 24, 29-49. [CrossRef]

28. Song, C.H. Development of Manufacturing Process and Testing for Thick Curved Thermoplastic Composite Tubes Made by Automated Fiber Placement. Masters Thesis, Concordia University, Montreal, QC, Canada, 2018.

29. LeGault, M. Building a Better Tail Boom. Compos. World. Available online: www.compositesworld.com/ articles/building-a-better-tail-boom (accessed on 12 October 2020).

30. Henne, F.; Ehar, S.; Kollmannsberger, A.; Hoeck, B.; Sause, M.; Drechsler, K. Thermoplastic in-situ fiber placement for future solid rocket motor casing manufacturing. In Proceedings of the SAMPE Europe SETEC, Tampere, Sweden, 10-11 September 2014.

31. Murray, B.R.; Doyle, A.; Feerick, P.; Semprimoschnig, C.O.; Leen, S.B.; Ó Brádaigh, C.M. Rotational moulding of PEEK polymer liners with carbon fibre/PEEK over tape-placement for space cryogenic fuel tanks. Mater. Des. 2017, 132, 567-581. [CrossRef]

32. Oliveri, V.; Peeters, D.; Clancy, G.J.; Jones, D.; O’Higgins, R.; Weaver, P.M. Design, Optimization and Manufacturing of a Unitized Carbon Fiber/Thermoplastic Wingbox Structure; American Institute of Aeronautics and Astronautics: Reston, VA, USA, 2018; ISBN 9781624105326.

33. Peeters, D.; Clancy, G.J.; Oliveri, V.; O’Higgins, R.; Jones, D.; Weaver, P.M. Thermoplastic Composite Stiffener Design with Manufacturing Considerations. In 2018 AIAA/ASCE/AHS/ASC Structures, Structural Dynamics, and Materials Conference; AIAA: Reston, VA, USA, 2018; ISBN 9781624105326.

34. Di Francesco, M.; Veldenz, L.; DellÁnno, G.; Potter, K. Heater power control for multi-material, variable speed Automated Fibre Placement. Compos. Part A Appl. Sci. Manuf. 2017, 101, 408-421. [CrossRef]

35. Hoang, M.D. Procedure for Making Flat Thermoplastic Composite Plates by Automated Fiber Placement and Their Mechanical Properties. Ph.D. Thesis, Concordia University, Montreal, QC, Canada, 2015. 
36. Vaidya, U.K.; Chawla, K.K. Processing of fibre reinforced thermoplastic composites. Int. Mater. Rev. 2008, 53, 185-218. [CrossRef]

37. Schaefer, P.M. Material characterization for determining the consolidation properties of carbon fiber tapes with PA-6 matrix. In Proceedings of the 20th International Conference on Composite Materials, Groningen, The Netherlands, 19-24 July 20152015.

38. Parlevliet, P.P.; Bersee, H.E.; Beukers, A. Residual stresses in thermoplastic composites—A study of the literature-part I: Formation of residual stresses. Compos. Part A Appl. Sci. Manuf. 2006, 37, 1847-1857. [CrossRef]

39. Parlevliet, P.P.; Bersee, H.E.; Beukers, A. Residual stresses in thermoplastic composites-A study of the literature-part II: Experimental techniques. Compos. Part A Appl. Sci. Manuf. 2007, 38, 651-665. [CrossRef]

40. Parlevliet, P.P.; Bersee, H.E.; Beukers, A. Residual stresses in thermoplastic composites—A study of the literature-part III: Effects of thermal residual stresses. Compos. Part A Appl. Sci. Manuf. 2007, 38, 1581-1596. [CrossRef]

41. Sonmez, F.O.; Hahn, H.T.; Akbulut, M. Analysis of Process-Induced Residual Stresses in Tape Placement. J. Thermoplast. Compos. Mater. 2002, 15, 525-544. [CrossRef]

42. August, Z.; Ostrander, G.; Michasiow, J.; Hauber, D. Recent Developments in Automated Fiber Placement of Thermoplastic Composites. SAMPE J. 2014, 50, 30-37.

43. Funck, R.; Neitzel, M. Improved thermoplastic tape winding using laser or direct-flame heating. Compos. Manuf. 1995, 6, 189-192. [CrossRef]

44. Lee, M. Heat Transfer and Consolidation Modeling of Composite Fiber Tow in Fiber Placement. Ph.D. Thesis, Virginia Polytechnic Institute and State University, Blacksburg, Virginia, 2004.

45. Haake, J. High power diode laser-assisted fiber placement of composite structure. In Proceedings of the ICALEO 2005: 24th International Congress on Laser Materials Processing and Laser Microfabrication, Miami, FL, USA, 31 October-3 November 2005.

46. Schledjewski, R.; Miaris, A. Thermoplastic tape placement by means of diode laser heating. In Proceedings of the SAMPE'09 Spring Symposium Conference, Baltimore, MD, USA, 19-21 May 2009.

47. Tierney, J.; Gillespie, J.W. Modeling of Heat Transfer and Void Dynamics for the Thermoplastic Composite Tow-Placement Process. J. Compos. Mater. 2003, 37, 1745-1768. [CrossRef]

48. Barasinski, A.; Leygue, A.; Soccard, E.; Poitou, A. In situ consolidation for thermoplastic tape placement process is not obvious. In AIP Conference Proceedings; American Institute of Physics: College Park, MD, USA, 2011; Volume 1353, pp. 948-953.

49. Barasinski, A.; Leygue, A.; Soccard, E.; Poitou, A.; Chinesta, F.; Chastel, Y.; El Mansori, M. An Improvement in Thermal Modelling of Automated Tape Placement Process. In AIP Conference Proceedings; American Institute of Physics: College Park, MD, USA, 2011; Volume 1315, pp. 185-190.

50. Maurer, D.; Mitschang, P. Laser-powered tape placement process simulation and optimization. Adv. Manuf. Polym. Compos. Sci. 2015, 1, 129-137.

51. Stokes-Griffin, C.; Compston, P. A combined optical-thermal model for near-infrared laser heating of thermoplastic composites in an automated tape placement process. Compos. Part A Appl. Sci. Manuf. 2015, 75, 104-115. [CrossRef]

52. Di Francesco, M.; Giddings, P.F.; Scott, M.; Goodman, E.; Dell Ánno, G.; Potter, K. Influence of laser power density on the meso-structure of thermoplastic composite preforms manufactured by automated fibre placement. In Proceedings of the International SAMPE Technical Conference, Long Beach, CA, USA, 23-26 May 2016.

53. Köhler, B.; Noeske, A.; Kindervater, T.; Wessollek, A.; Brand, T.; Biesenbach, J. 11-kW direct diode laser system with homogenized $55 \times 20 \mathrm{~mm} 2$ top-hat intensity distribution. In High-Power Diode Laser Technology and Applications V; International Society for Optics and Photonics: Bellingham, WA, USA, 2007; Volume 6456, p. 645600.

54. Homburg, O.; Bayer, A.; Mitra, T.; Meinschien, J.; Aschke, L. Beam shaping of high power diode lasers benefits from asymmetrical refractive microlens arrays. In High-Power Diode Laser Technology and Applications VI; International Society for Optics and Photonics: San Jose, CA, USA, 2008; Volume 6876.

55. Brecher, C.; Emonts, M.; Stimpfl, J. $\mathrm{CO}_{2}$-Laser-assisted production of hybrid fiber-reinforced thermoplastic composites. In Proceedings of the ICCM19, Montréal, QC, Canada, 28 July 2013. 
56. Rizzolo, R.H.; Walczyk, D.F. Ultrasonic consolidation of thermoplastic composite prepreg for automated fiber placement. J. Thermoplast. Compos. Mater. 2016, 29, 1480-1497. [CrossRef]

57. Chu, Q.; Li, Y.; Xiao, J.; Huan, D.; Zhang, X.; Chen, X. Processing and characterization of the thermoplastic composites manufactured by ultrasonic vibration assisted automated fiber placement. J. Thermoplast. Compos. Mater. 2018, 31, 339-358. [CrossRef]

58. Lichtinger, R.; Hörmann, P.; Stelzl, D.; Hinterhölzl, R. The effects of heat input on adjacent paths during Automated Fibre Placement. Compos. Part A Appl. Sci. Manuf. 2015, 68, 387-397. [CrossRef]

59. Weiler, T.; Emonts, M.; Janssen, H. On the use of flexible intensity distributions for thermoplastic tape placement by means of VCSEL. In Proceedings of the ITHEC 2016, 3rd International Conference on Thermoplastic Composites, Bremen, Germany, 10 November 2016.

60. Grove, S. Thermal modelling of tape laying with continuous carbon fibre reinforced thermoplastic. Composites 1988, 19, 367-375. [CrossRef]

61. Saliba, T.E.; Anderson, D.P.; Servais, R.A. Process Modeling of Heat Transfer and Crystallization in Complex Shapes Thermoplastic Composites. J. Thermoplast. Compos. Mater. 1989, 2, 91-104. [CrossRef]

62. Ghasemi Nejhad, M.; Cope, R.; Güceri, S. Thermal Analysis of In-Situ Thermoplastic Composite Tape Laying. J. Thermoplast. Compos. Mater. 1991, 4, 20-45. [CrossRef]

63. Pitchumani, R.; Ranganathan, S.; Don, R.; Gillespie, J.; Lamontia, M. Analysis of transport phenomena governing interfacial bonding and void dynamics during thermoplastic tow-placement. Int. J. Heat Mass Transf. 1996, 39, 1883-1897. [CrossRef]

64. Kim, H.J.; Kim, S.K.; Lee, W.I. A study on heat transfer during thermoplastic composite tape lay-up process. Exp. Therm. Fluid Sci. 1996, 13, 408-418. [CrossRef]

65. Sonmez, F.O.; Hahn, H.T. Analysis of the On-Line Consolidation Process in Thermoplastic Composite Tape Placement. J. Thermoplast. Compos. Mater. 1997, 10, 543-572. [CrossRef]

66. Toso, Y.M.P. Effective Automated Tape Winding Process with On-Line Bonding under Transient Thermal Conditions. Ph.D. Thesis, ETH Zurich, Zürich, Switzerland, 2003.

67. Tumkor, S.; Turkmen, N.; Chassapis, C.; Manoochehri, S. Modeling of heat transfer in thermoplastic composite tape lay-up manufacturing. Int. Commun. Heat Mass Transf. 2001, 28, 49-58. [CrossRef]

68. Heider, D.; Piovoso, M.J.; Gillespie, J.W., Jr. Application of a neural network to improve an automated thermoplastic tow-placement process. J. Process Control 2002, 12, 101-111. [CrossRef]

69. Tierney, J.; Gillespie, J.W. Modeling of In Situ Strength Development for the Thermoplastic Composite Tow Placement Process. J. Compos. Mater. 2006, 40, 1487-1506. [CrossRef]

70. Schlottermuller, M.; Lu, H.; Roth, Y.; Himmel, N.; Schledjewski, R.; Mitschang, P. Thermal Residual Stress Simulation in Thermoplastic Filament Winding Process. J. Thermoplast. Compos. Mater. 2003, 16, 497-519. [CrossRef]

71. Grouve, W. Weld Strength of Laser-Assisted Tape-Placed Thermoplastic Composites. Ph.D. Thesis, University of Twente, Enschede, The Netherlands, 2012.

72. Duhovic, M.; Hümbert, M.; Mitschang, P.; Maier, M.; Caldichoury, I.; L'Eplattenier, P. Further advances in simulating the processing of composite materials by electromagnetic induction. In Proceedings of the 13th International LS-DYNA Conference, Detroit, MI, USA, 8-10 June 2014.

73. Han, Z.; Cao, Z.; Shao, Z.; Fu, H. Parametric study on heat transfer for tow placement process of thermoplastic composite. Polym. Polym. Compos. 2014, 22, 713-722. [CrossRef]

74. Li, Z.; Yang, T.; Du, Y. Dynamic finite element simulation and transient temperature field analysis in thermoplastic composite tape lay-up process. J. Thermoplast. Compos. Mater. 2015, 28, 558-573. [CrossRef]

75. Phillips, R.; Sunderland, P.; Kim, P.; Manson, J.-A.E. Influence of processing parameters on the dimensional stability of polymer composites. Int. Workshop Adv. Mater. High-Precis. Detect. 1994, 171-178. [CrossRef]

76. Kergomard, Y.D. 3D Thermo-mechanical model based simulation of the welding of thermoplastic composite tape using automated tape laying (ATL) process. In Proceedings of the 20th International Conference Composite Materials, Copenhagen, Denmark, 19-24 July 2015.

77. Weiler, T.; Emonts, M.; Wollenburg, L.; Janssen, H. Transient thermal analysis of laser-assisted thermoplastic tape placement at high process speeds by use of analytical solutions. J. Thermoplast. Compos. Mater. 2018, 31, 311-338. [CrossRef] 
78. Weiler, T.; Emonts, M.; Striet, P.; Gronenborn, S.; Janssen, H. Optical modelling of VCSEL assisted thermoplastic tape placement. In Proceedings of the 17th European Conference on Composite Materials, (ECCM17), Munich, Germany, 26-30 June 2016.

79. Pistor, C.; Yardimci, M.; Güçeri, S. On-line consolidation of thermoplastic composites using laser scanning. Compos. Part A Appl. Sci. Manuf. 1999, 30, 1149-1157. [CrossRef]

80. Hassan, N.; Thompson, J.E.; Batra, R.C.; Hulcher, A.B.; Song, X.; Loos, A.C. A Heat Transfer Analysis of the Fiber Placement Composite Manufacturing Process. J. Reinf. Plast. Compos. 2005, 24, 869-888. [CrossRef]

81. Nicodeau, C. Modélisation du Soudage en Continu de Composites à Matrice Thermoplastique. Ph.D. Thesis, ENSAM, Paris, France, 2005.

82. Li, Y.H.; Fu, H.Y.; Shao, Z.X. The Influence of Preheating on Automated Fiber Placement Speed. Adv. Mater. Res. 2011, 213, 136-142. [CrossRef]

83. Lamèthe, J.-F. Etude de L'adhésion de Composites Thermoplastiques Semi-Cristallins; Application à la Mise en Oeuvre par Soudure. Ph.D. Thesis, Université Pierre et Marie Curie-Paris VI, Paris, France, 2004.

84. Lamèthe, J.-F.; Beauchêne, P.; Léger, L. Polymer dynamics applied to PEEK matrix composite welding. Aerosp. Sci. Technol. 2005, 9, 233-240. [CrossRef]

85. Barasinski, A.; Leygue, A.; Soccard, E.; Poitou, A. Identification of non-uniform thermal contact resistance in automated tape placement process. Int. J. Mater. Form. 2014, 7, 479-486. [CrossRef]

86. Bur, N.; Joyot, P.; Ghnatios, C.; Villon, P.; Cueto, E.; Chinesta, F. On the use of model order reduction for simulating automated fibre placement processes. Adv. Modeling Simul. Eng. Sci. 2016, 3, 1-8. [CrossRef]

87. Perez, M.; Barasinski, A.; Courtemanche, B.; Ghnatios, C.; Abisset-Chavanne, E.; Chinesta, F. Simulation du comportement thermique du procédé d'enroulement filamentaire de composites thermoplastiques assisté par chauffage laser. Journées Nationale Composites 2017.

88. Schaefer, P.; Gierszewski, D.; Kollmannsberger, A.; Zaremba, S.; Drechsler, K. Analysis and improved process response prediction of laser-assisted automated tape placement with PA-6/carbon tapes using Design of Experiments and numerical simulations. Compos. Part A Appl. Sci. Manuf. 2017, 96, 137-146. [CrossRef]

89. Stokes-Griffin, C.; Compston, P. The effect of processing temperature and placement rate on the short beam strength of carbon fibre/PEEK manufactured using a laser tape placement process. Compos. Part A Appl. Sci. Manuf. 2015, 78, 274-283. [CrossRef]

90. Stokes-Griffin, C.; Compston, P. Optical characterization and modelling for oblique near-infrared laser heating of carbon fibre reinforced thermoplastic composites. Opt. Lasers Eng. 2015, 72, 1-11. [CrossRef]

91. Stokes-Griffin, C.; Compston, P. An inverse model for optimisation of laser heat flux distributions in an automated laser tape placement process for carbon fibre/PEEK. Compos. Part A Appl. Sci. Manuf. 2016, 88, 190-197. [CrossRef]

92. Pignon, B.; Boyard, N.; Sobotka, V.; Delaunay, D. Heat transfer analysis at high cooling rate on the surface of thermoplastic parts. Int. J. Heat Mass Transf. 2017, 106, 253-262. [CrossRef]

93. Shih, P.-J. On-Line Consolidation of Thermoplastic Composites. Ph.D. Thesis, Virginia Tech, Blacksburg, VA, USA, 1997.

94. Lionetto, F.; Dell'Anna, R.; Montagna, F.; Maffezzoli, A. Modeling of continuous ultrasonic impregnation and consolidation of thermoplastic matrix composites. Compos. Part A Appl. Sci. Manuf. 2016, 82, 119-129. [CrossRef]

95. Romoli, L.; Fischer, F.; Kling, R. A study on UV laser drilling of PEEK reinforced with carbon fibers. Opt. Lasers Eng. 2012, 50, 449-457. [CrossRef]

96. Nichelatti, E. Complex refractive index of a slab from reflectance and transmittance: Analytical solution. J. Opt. A Pure Appl. Opt. 2002, 4, 400-403. [CrossRef]

97. Reichardt, J.; Baran, I.; Akkerman, R. New analytical and numerical optical model for the laser assisted tape winding process. Compos. Part A Appl. Sci. Manuf. 2018, 107, 647-656. [CrossRef]

98. Oromiehie, E.; Prusty, B.G.; Compston, P.; Rajan, G. In situ process monitoring for automated fibre placement using fibre Bragg grating sensors. Struct. Health Monit. Int. J. 2016, 15, 706-714. [CrossRef]

99. del Saenz Castillo, D.; Martin, I.; Rodriguez-Lence, F.; Güemes, A. On-line monitoring of a laser assisted fiber placement process with CFR thermoplastic matrix by using Fiber Bragg Gratings. In Proceedings of the 8th European Workshop on Structural Health Monitoring (EWSHM 2016), Bilbao, Spain, 5-8 July 2016. 
100. del Saenz Castillo, D.; Martin, I.; Calvo, S.; Güemes, A. Real-time monitoring of thermal history of thermoplastic automatic lamination with FBG sensors and process modelling validation. Smart Mater. Struct. 2020, 29, 115004. [CrossRef]

101. Khan, S. Thermal Control System Design for Automated Fiber Placement Process. Ph.D. Thesis, Concordia University, Montreal, QC, Canada, 2011.

102. Loos, A.C.; Dara, P.H. Processing of thermoplastic matrix composites. In Review of Progress in Quantitative Nondestructive Evaluation; Springer: Berlin/Heidelberg, Germany, 1987; pp. 1257-1265, ISBN 9781461290544/9781461318934.

103. Yang, F.; Pitchumani, R. A fractal Cantor set based description of interlaminar contact evolution during thermoplastic composites processing. J. Mater. Sci. 2001, 36, 4661-4671. [CrossRef]

104. Yang, F.; Pitchumani, R. Healing of Thermoplastic Polymers at an Interface under Nonisothermal Conditions. Macromolecules 2002, 35, 3213-3224. [CrossRef]

105. Yang, F.; Pitchumani, R. Interlaminar contact development during thermoplastic fusion bonding. Polym. Eng. Sci. 2002, 42, 424-438. [CrossRef]

106. Yang, F.; Pitchumani, R. Nonisothermal healing and interlaminar bond strength evolution during thermoplastic matrix composites processing. Polym. Compos. 2003, 24, 263-278. [CrossRef]

107. Khan, M.A.; Schledjewski, R. Influencing factors for an online consolidating thermoplastic tape placement process. In Proceedings of the 17th International Conference on Composite Materials, ICCM-17, Edinburgh, UK, 27-31 July 2009.

108. Stokes-Griffin, C.; Compston, P. Investigation of sub-melt temperature bonding of carbon fibre/PEEK in an automated laser tape placement process. Compos. Part A Appl. Sci. Manuf. 2016, 84, 17-25. [CrossRef]

109. Schaefer, P.; Guglhoer, T.; Sause, M.; Drechsler, K. Development of intimate contact during processing of carbon fiber reinforced Polyamide-6 tapes. J. Reinf. Plast. Compos. 2017, 36, 593-607. [CrossRef]

110. Levy, A.; Heider, D.; Tierney, J.; Gillespie, J.W. Inter-layer thermal contact resistance evolution with the degree of intimate contact in the processing of thermoplastic composite laminates. J. Compos. Mater. 2014, 48, 491-503. [CrossRef]

111. Perez, M.; Leon, A.; Dedieu, C.; Argerich, C.; Defoort, B.; Dupillier, J.M.; Soccard r Barasinski, A.; Chinesta, F. Keys for designing the most efficient and robust in-situ TP ATP. In Proceedings of the 6th International Carbon Composites Conference, Arcachon, France, 4-6 June 2018.

112. Yu, T.; Shi, Y.; He, X.; Kang, C.; Deng, B. Modeling and optimization of interlaminar bond strength for composite tape winding process. J. Reinf. Plast. Compos. 2017, 36, 579-592. [CrossRef]

113. Marchello, J.M.; Messier, B.C. Effect of Pressure in Thermoplastic Ribbon Thermal Welding; NASA-TR-20040110360 Langley Research Center: Hampton, VA, USA, 1996.

114. Mantell, S.C.; Springer, G.S. Manufacturing Process Models for Thermoplastic Composites. J. Compos. Mater. 1992, 26, 2348-2377. [CrossRef]

115. de Gennes, P.G. Reptation of a Polymer Chain in the Presence of Fixed Obstacles. J. Chem. Phys. 1971, 55, 572-579. [CrossRef]

116. De Gennes, P.; Leger, L. Dynamics of entangled polymer chains. Annu. Rev. Phys. Chem. 1982, 33, 49-61. [CrossRef]

117. Reptation and Tube Model. Available online: http://polymerdatabase.com/polymer\%20physics/Reptation. html (accessed on 22 August 2020).

118. Bastien, L.J.; Gillespie, J.W. A non-isothermal healing model for strength and toughness of fusion bonded joints of amorphous thermoplastics. Polym. Eng. Sci. 1991, 31, 1720-1730. [CrossRef]

119. Sonmez, F.O.; Akbulut, M. Process optimization of tape placement for thermoplastic composites. Compos. Part A Appl. Sci. Manuf. 2007, 38, 2013-2023. [CrossRef]

120. Zhao, P.; Shirinzadeh, B.; Shi, Y.; Cheuk, S.; Clark, L. Multi-pass layup process for thermoplastic composites using robotic fiber placement. Robot. Comput. Integr. Manuf. 2018, 49, 277-284. [CrossRef]

121. Quan, H.; Li, Z.-M.; Yang, M.-B.; Huang, R. On transcrystallinity in semi-crystalline polymer composites. Compos. Sci. Technol. 2005, 65, 999-1021. [CrossRef]

122. Tierney, J.J.; Gillespie, J., Jr. Crystallization kinetics behavior of PEEK based composites exposed to high heating and cooling rates. Compos. Part A Appl. Sci. Manuf. 2004, 35, 547-558. [CrossRef] 
123. Guan, X.; Pitchumani, R. Modeling of spherulitic crystallization in thermoplastic tow-placement process: Spherulitic microstructure evolution. Compos. Sci. Technol. 2004, 64, 1363-1374. [CrossRef]

124. Lee, K.; Weitsman, Y. Effects of Nonuniform Crystallinity on Stress Distributions in Cross-Ply Graphite/PEEK (APC-2] Laminates. J. Compos. Mater. 1991, 25, 1143-1157. [CrossRef]

125. Yu, T.; Wu, C.M.; Chang, C.Y.; Wang, C.Y.; Rwei, S.P. Effects of crystalline morphologies on the mechanical properties of carbon fiber reinforcing polymerized cyclic butylene terephthalate composites. Express Polym. Lett. 2012, 6, 318-328. [CrossRef]

126. Regis, M.; Bellare, A.; Pascolini, T.; Bracco, P. Characterization of thermally annealed PEEK and CFR-PEEK composites: Structure-properties relationships. Polym. Degrad. Stab. 2017, 136, 121-130. [CrossRef]

127. Tregub, A.; Harel, H.; Marom, G.; Migliaresi, C. The influence of thermal history on the mechanical properties of poly(ether ether ketone) matrix composite materials. Compos. Sci. Technol. 1993, 48, 185-190. [CrossRef]

128. Cebe, P.; Chung, S.Y.; Hong, S.-D. Effect of thermal history on mechanical properties of polyetheretherketone below the glass transition temperature. J. Appl. Polym. Sci. 1987, 33, 487-503. [CrossRef]

129. Lee, I.-G.; Kim, D.-H.; Jung, K.-H.; Kim, H.-J.; Kim, H.-S. Effect of the cooling rate on the mechanical properties of glass fiber reinforced thermoplastic composites. Compos. Struct. 2017, 177, 28-37. [CrossRef]

130. Gao, S.-L.; Kim, J.-K. Crystallinity and interphase properties of carbon fiber/PEEK matrix composites. In Proceedings of the 12th International Conference Composite Materials (ICCM-12), Paris, France, 5-9 July 1999.

131. Gao, S.-L.; Kim, J.-K. Cooling rate influences in carbon fibre/PEEK composites. Part I. Crystallinity and interface adhesion. Compos. Part A Appl. Sci. Manuf. 2000, 31, 517-530. [CrossRef]

132. Gao, S.-L.; Kim, J.-K. Cooling rate influences in carbon fibre/PEEK composites. Part II: Interlaminar fracture toughness. Compos. Part A Appl. Sci. Manuf. 2001, 32, 763-774. [CrossRef]

133. Gao, S.-L.; Kim, J.-K. Cooling rate influences in carbon fibre/PEEK composites. Part III: Impact damage performance. Compos. Part A Appl. Sci. Manuf. 2001, 32, 775-785. [CrossRef]

134. Ray, D.; Comer, A.J.; Lyons, J.; Obande, W.; Jones, D.; Higgins, R.M.; McCarthy, M.A. Fracture toughness of carbon fiber/polyether ether ketone composites manufactured by autoclave and laser-assisted automated tape placement. J. Appl. Polym. Sci. 2014, 132, 41643. [CrossRef]

135. Gao, S.-L.; Kim, J.-K. Correlation among crystalline morphology of PEEK, interface bond strength, and in-plane mechanical properties of carbon/PEEK composites. J. Appl. Polym. Sci. 2002, 84, 1155-1167. [CrossRef]

136. El Kadi, H.; Denault, J. Effects of Processing Conditions on the Mechanical Behavior of Carbon-Fiber-Reinforced PEEK. J. Thermoplast. Compos. Mater. 2001, 14, 34-53. [CrossRef]

137. Toft, M. The Effect of Crystalline Morphology on the Glass Transition and Enthalpic Relaxation in Poly (Ether-Ether-Ketone). Ph.D. Thesis, University of Birmingham, Birmingham, UK, 2012.

138. Fink, B.K.; Gillespie, J.W., Jr.; Ersoy, N.B. Thermal degradation effects on consolidation and bonding in the thermoplastic fibre-placement process. In Report nb ARL-TR-2238; Army Research Lab., Aberdeen Proving Ground: Adelphi, MD, USA, 2000.

139. Beyler, C.L.; Hirschler, M.M. Thermal decomposition of polymers. In SFPE Handbook of Fire Protection Engineering; Springer: New York, NY, USA, 2002; Volume 2, pp. 111-131, ISBN 978-1-4939-2565-0.

140. Hancox, N. Thermal effects on polymer matrix composites: Part 2. Thermal degradation. Mater. Des. 1998, 19, 93-97. [CrossRef]

141. Patel, P.; Hull, T.R.; McCabe, R.W.; Flath, D.; Grasmeder, J.; Percy, M. Mechanism of thermal decomposition of poly(ether ether ketone) (PEEK) from a review of decomposition studies. Polym. Degrad. Stab. 2010, 95, 709-718. [CrossRef]

142. Nandan, B.; Kandpal, L.; Mathur, G. Poly(ether ether keto-ne)/poly(aryl ether sulphone) blends: Thermal degradation behaviour. Eur. Polym. J. 2003, 39, 193-198. [CrossRef]

143. Bayerl, T.; Brzeski, M.; Martínez-Tafalla, M.; Schledjewski, R.; Mitschang, P. Thermal degradation analysis of short-time heated polymers. J. Thermoplast. Compos. Mater. 2015, 28, 390-414. [CrossRef]

144. Tsotra, P.; Toma, M.; Pascual, A.; Schadt, F.; Brauner, C.; Dransfeld, C. Thermo-oxidative degradation of PEEK at high temperatures. In Proceedings of the 18th European Conference on Composite Materials, ECCM18, Athens, Greece, 25-28 June 2018. 
145. Parandoush, P.; Tucker, L.; Zhou, C.; Lin, D. Laser assisted additive manufacturing of continuous fiber reinforced thermoplastic composites. Mater. Des. 2017, 131, 186-195. [CrossRef]

146. Martin, M.I.; Rodríguez-Lence, F.; Güemes, A.; Fernández-López, A.; Pérez-Maqueda, L.A.; Perejón, A. On the determination of thermal degradation effects and detection techniques for thermoplastic composites obtained by automatic lamination. Compos. Part A Appl. Sci. Manuf. 2018, 111, 23-32. [CrossRef]

(C) 2020 by the authors. Licensee MDPI, Basel, Switzerland. This article is an open access article distributed under the terms and conditions of the Creative Commons Attribution (CC BY) license (http://creativecommons.org/licenses/by/4.0/). 